IZA DP No. 8217

Are Teams Less Inequality Averse than Individuals?

Haoran He

Marie Claire Villeval

May 2014 


\title{
Are Teams Less Inequality Averse than Individuals?
}

\author{
Haoran He \\ Beijing Normal University \\ Marie Claire Villeval \\ Université de Lyon, CNRS, GATE \\ and IZA \\ Discussion Paper No. 8217 \\ May 2014 \\ IZA \\ P.O. Box 7240 \\ 53072 Bonn \\ Germany \\ Phone: +49-228-3894-0 \\ Fax: +49-228-3894-180 \\ E-mail: iza@iza.org
}

Any opinions expressed here are those of the author(s) and not those of IZA. Research published in this series may include views on policy, but the institute itself takes no institutional policy positions. The IZA research network is committed to the IZA Guiding Principles of Research Integrity.

The Institute for the Study of Labor (IZA) in Bonn is a local and virtual international research center and a place of communication between science, politics and business. IZA is an independent nonprofit organization supported by Deutsche Post Foundation. The center is associated with the University of Bonn and offers a stimulating research environment through its international network, workshops and conferences, data service, project support, research visits and doctoral program. IZA engages in (i) original and internationally competitive research in all fields of labor economics, (ii) development of policy concepts, and (iii) dissemination of research results and concepts to the interested public.

IZA Discussion Papers often represent preliminary work and are circulated to encourage discussion. Citation of such a paper should account for its provisional character. A revised version may be available directly from the author. 


\section{ABSTRACT}

\section{Are Teams Less Inequality Averse than Individuals?*}

We compare inequality aversion in individuals and teams by means of both within- and between-subject experimental designs, and we investigate how teams aggregate individual preferences. We find that team decisions reveal less inequality aversion than individual initial proposals in team decision-making. However, teams are no more selfish than individuals who decide in isolation. Individuals express strategically more inequality aversion in their initial proposals in team decision-making because they anticipate the selfishness of other members. Members with median social preferences drive team decisions. Finally, we show that social image has little influence because guilt and envy are almost similar in anonymous and non-anonymous interactions.

JEL Classification: C91, C92, D03, D63, D72

Keywords: team, inequity aversion, preference aggregation, social image, experiment

Corresponding author:

Marie Claire Villeval

GATE

CNRS - University of Lyon

93 Chemin des Mouilles

69130 Ecully

France

E-mail: villeval@gate.cnrs.fr

\footnotetext{
* We are grateful to participants at the Asia-Pacific Meeting of the Economic Science Association in Auckland and the ASFEE conference in Besançon for their useful comments. We thank Weiyao Wang and Pengyuan Pei for excellent research assistance. This research program has been supported by a grant from the LABEX CORTEX (ANR-11-LABX-0042) of Université de Lyon, France, within the program "Investissements d'Avenir" (ANR-11-IDEX-007) operated by the French National Research Agency (ANR), and a grant from the National Natural Science Foundation of China (Proj. No. 71303022).
} 


\section{INTRODUCTION}

Social comparisons are widespread in human societies. Most individuals compare their performance, their wealth, and their opportunities to those of relevant others, and differences affect their utility. While a fraction of individuals enjoy outperforming others, many other individuals are inequality averse. In economic models such as Fehr and Schmidt's (1999) and Bolton and Ockenfels' (2000), which have refined Bolton's (1991) model of fairness, inequality aversion captures the fact that people care not only about their own material payoff but also about the distribution of payoffs between them and others. To date, the literature on inequality aversion has almost exclusively considered individual preferences. Yet, groups might also suffer from guilt and envy when comparing themselves to other groups. This possibility is particularly relevant when a group feels discriminated against by another group or when its perspectives are lower compared to others'. This issue is important because inequality aversion between groups may lead to social conflicts.

If teams may be inequality averse, it is unclear whether this social preference is stronger or weaker than in individuals. We explore this issue by addressing three main questions. First, we analyze whether guilt and envy in various allocation tasks differ between individuals and teams. Second, we investigate whether individuals' initial choices, that will be aggregated in a team decision, differ from choices made in isolation, revealing the role of the decision-making context. Third, we study how social image concerns affect team decision-making when interactions within teams are no longer anonymous.

The first research question relates to measuring the difference in preferences between individuals and teams. Many previous studies using a variety of games have found that teams behave more rationally and selfishly than individuals (see Charness and Sutter, 2012), while others find that the difference depends crucially on the nature of the task and on the decision-making 
procedure (e.g., Kocher and Sutter, 2007). These studies did not explore inequality aversion. A recent exception is Balafoutas et al. (2014), who show that unitary teams express the same guilt as individuals; they are more benevolent than individuals in the domain of disadvantageous inequality, and they are more efficiency-oriented. Our hypothesis is that individual decisions reveal more inequality aversion than team decisions given that a more inequality averse individual in a team imposes a sacrifice on all team members. However, this process may depend on the decision-making procedure and, in particular, on whether the anonymity of team members is preserved or not during the aggregation process.

Our second research question examines the aggregation of individual preferences to form the team's decision. We compare the individual allocation decisions made in isolation and those made in a team environment in which unanimity is required to form the team decision. A purely selfish person should make the same individual decisions in both an isolated and a team context. However, pro-social individuals may submit more inequality averse proposals within a team than in an isolated context if they believe that they are matched with selfish members to increase the degree of equality in the team's final decision.

The third question investigates how the degree of anonymity affects individual initial proposals in teams and their adjustment during the aggregation process. In real settings, collective choices by juries, boards, and families usually result from non-anonymous interactions. When it is common information that a proposal emanates from a specific team member, allocation choices are expected to express more inequality aversion than when choices are made anonymously, due to social image concerns (see, e.g., Benabou and Tirole, 2006) because team members can assign personal responsibility to a specific member. Social image concerns may also slow down the convergence to a team decision, as people may be more reluctant to revise their proposals in the direction of 
selfishness. In contrast, anonymity may facilitate convergence to the group norm because of deindividuation (Reicher et al., 1995).

To address these questions, we have designed a laboratory experiment that allows us to compare inequality aversion between individuals and teams. We elicit inequality aversion at the individual level by means of allocation tasks introduced by Blanco et al. (2011), specifically an Ultimatum Bargaining Game and a Modified Dictator Game. Blanco et al. (2011) used these tasks to test the model of Fehr and Schmidt (1999) using a within-subject design. Our contribution is to adapt this design to elicit advantageous and disadvantageous inequality aversion at the team level when all team members receive the same payoff. Pairs of three-player teams perform the same allocation tasks. The team decisions result from votes made under a unanimity rule: under a time limit, voting is repeated until unanimity is reached. Using a within-subject design allows us to compare individual's decisions made in isolation and their initial proposals within a team. Thus, we contribute to the literature on how individual preferences are aggregated in groups (Zhang and Casari, 2012; Ambrus et al., 2013). Another contribution is studying how social image affects team preferences. Using a between-subjects design, we compare a treatment in which individual proposals in teams are anonymous and a treatment in which subjects can identify team members' specific proposals. Furthermore, we test the predictive value of our estimated guilt and envy parameters by means of the Production Game designed by Yang et al. (2013) both in its original individual version and in our team environment.

We have five primary findings. First, although this experiment was conducted in China, we find estimates for envy and guilt at the individual level similar to those found in Blanco et al. (2011), which was conducted in the U.K. Finding no difference in inequality aversion between a communist country and a traditionally market-oriented economy is interesting because of the huge differences 
in cultural and political backgrounds. Second, we find no within- or between-subject differences between individual and team advantageous and disadvantageous inequality aversion. Third, the initial proposals made by individuals in a team context show more inequality aversion than the individual proposals made in isolation by the same subjects. This effect is not driven by social image concerns, as we find no difference between proposals made anonymously and non-anonymously. This result stems from the fact that in the absence of information about team members' preferences, inequality averse individuals adjust their initial proposals strategically in the direction of higher inequality aversion, probably anticipating more selfish behavior or more pressure from team members. Fourth, the higher heterogeneity of team members in terms of guilt and envy increases the number of iterations until convergence. Consistent with Ambrus et al. (2013), we find that in the aggregation process, individuals with median preferences drive the team decision, while selfish and more inequality averse individuals converge more slowly to the proposals made by the median members. Finally, if the guilt parameter predicts the advantaged team's behavior in the Production Game when choices are not anonymous, the envy parameter shows no predictive power in any configuration of this game. This result suggests that this parameter captures a mixture of inequality aversion and other motives that do not influence behavior in the Production Game. Alternatively, it might be that preferences are not stable across games.

The remainder of this paper is organized as follows. Section 2 briefly reviews the related literature. Section 3 presents the experimental design and procedures. Section 4 analyzes the results, and Section 5 discusses these results and concludes the paper.

\section{RELATED LITERATURE}

Our paper connects the literature on inequality aversion and on team decision-making. Tests of individual inequality aversion models are first developed at the aggregate level (Fehr and Schmidt, 
1999; Bolton and Ockenfels, 2000). Then, several experimental studies attempted to elicit inequality aversion preferences at the individual level (e.g., Engelmann and Strobel, 2004; Bolton and Ockenfels, 2006; Dannenberg et al., 2007; Güth et al., 2009; Bartling et al., 2009; Blanco et al., 2011; Yang et al., 2013). For example, using a within-subject design, Blanco et al. (2011) elicit the advantageous inequality aversion (or guilt) and the disadvantageous inequality aversion (or envy) parameters in Fehr and Schmidt's model by means of two multiple price lists based on a Modified Dictator Game and an Ultimatum Game. They compare the performance of the model at both the aggregate and the individual levels and conclude that its predictive power is limited at the individual level. Yang et al. (2013) show the robustness of the inequality aversion model to efficiency concerns and variations in payoff scales.

Some studies have further conducted within-subject tests of the predictive power of the estimates using mixed evidence. In particular, Engelmann and Strobel (2004) find no support for either Fehr and Schmidt's model or Bolton and Ockenfels' model in a simple distribution game. In contrast, Dannenberg et al. (2007) show that the guilt parameter has some explanatory power for individual behavior in social dilemmas. These tests have used sequential-move prisoner's dilemma games (Blanco et al., 2011) or public good games (Blanco et al., 2011; Dannenberg et al., 2007). The novel production game introduced by Yang et al. (2013) has the advantage of providing precise normative standards in a rich environment offering more than binary choices and leaving no room for risk attitudes. Our contribution is adjusting the games used in Blanco et al. (2011) and the production game of Yang et al. (2013) to elicit inequity aversion in teams.

We also contribute to the literature on group decision-making. Many have found that teams behave more selfishly than individuals in various games (Kugler et al., 2012). ${ }^{1,2}$ This behavior may

\footnotetext{
${ }^{1}$ This result holds for dictator games (Luhan et al., 2009), sequential games such as ultimatum (Robert and Carnevale, 1997; Bornstein and Yaniv, 1998), trust (Cox, 2002; Kugler et al., 2007; Song, 2009), centipede (Bornstein et al., 2004),
} 
be due either to the fact that people behave differently in groups, to the higher persuasiveness of selfish people, or to the skewness of the distribution of preferences. ${ }^{3}$ Teams also behave more rationally in non-strategic interactions. ${ }^{4}$ Studies have examined how inequality aversion in teams affects the design of contracts (Bartling and von Siemens, 2010; Rey-Biel, 2008), sharing rules (Gill and Stone, 2012), peer pressure (Mohnen et al., 2008), sanction and cooperation (Masclet and Villeval, 2008; Kölle et al., 2011). However, the comparison between inequality aversion in individuals and in teams has remained almost unexplored. One exception is Balafoutas et al. (2014), who use a double price-list technique under both individual and team regimes. They find that teams eliminate choices consistent with inequality aversion and spitefulness and they favor choices that increase efficiency. They also find that efficiency-oriented team members are more assertive in the bargaining process. In contrast to these authors, we cannot isolate a preference for efficiency, but we can identify the role of image concerns in team preferences and we measure the predictive power of Fehr and Schmidt's model for teams in a Production game. ${ }^{5}$

The individual-team differences may depend crucially on the decision-making procedure. Most studies use face-to-face decision-making with unrestricted communication (Kocher and Sutter, 2005;

and power-to-take games (Bosman et al., 2006), as well as simultaneous games such as public goods (Van Vugt et al., 2007), beauty contests (Kocher and Sutter, 2005; Kocher et al., 2006; Sutter, 2005), and auctions (Cox and Hayne, 2006; Sutter et al., 2009; Sheremeta and Zhang, 2010; Casari et al., 2011; Cheung and Palan, 2011).

${ }^{2}$ Exceptions are as follows. Cason and Mui (1997) find that teams of two act less selfishly than individuals in a dictator game. This group polarization is due more to social comparisons (which give more weight to pro-social individuals) than to persuasion. Müller and Tan (2013) find less selfish team choices in sequential market games. Kocher and Sutter (2007) find mixed evidence in a gift-exchange game. Franzen and Pointner (2013) find no difference in a dictator game with communication.

${ }^{3}$ Ambrus et al. (2013) argue in favor of the third explanation. In groups, median members have a stronger influence because extremes on both sides neutralize each other. If the median member's preference is below the mean in terms of pro-social preferences, it drives the group choice toward greater selfishness.

${ }^{4}$ Teams make fewer mistakes (Fahr and Irlenbusch, 2011), suffer less from hindsight bias (Stahlberg et al., 1995), myopic loss aversion (Sutter, 2007), and overconfidence (Sniezek, 1992), are more risk averse (Baker et al., 2008; Shupp and Williams, 2008) or closer to risk neutrality (He et al., 2012) or take better risks (Rockenbach et al., 2007). ${ }^{5}$ There are other differences with our design. Fehr and Schmidt's experiment consists of two sessions, one for individual decisions and one for team decisions. In our case, all the games are played in a single session, and we alternate the order between team and individual decision-making. In their design, unanimity must be reached in five rounds maximum, while in our case, we apply a time constraint. 
Kocher et al., 2006; Kugler et al., 2007; Sutter et al., 2009; Ambrus et al., 2013). Bosman et al. (2006) find that the combination of the decision rule and the distribution of players' types determines the differences. Kocher and Sutter (2007) show that groups behave more selfishly than individuals in an anonymous computerized procedure but not in a face-to-face unrestricted communication protocol. We use the unanimity rule like Balafoutas et al. (2014), but we do not allow free communication. Moreover, we manipulate anonymity because it may affect the process of deindividuation within teams. ${ }^{6}$

\section{EXPERIMENTAL DESIGN AND PROCEDURES}

\subsection{The games}

\section{Individuals' inequality aversion}

To estimate the individuals' disadvantageous and advantageous inequality aversion parameters as defined in Fehr and Schmidt's model, we replicate two of the games used in Blanco et al. (2011). ${ }^{7}$ Each game consists of 21 decision problems, as shown in Table 1. The games are played under the veil of ignorance using the strategy method. ${ }^{8}$

The Ultimatum Game (UG, hereafter) involves a proposer and a responder. The proposer must share a pie of 400 points between himself and the responder. He makes an offer $S$ to the responder, keeping (400 - S) to himself. If the responder rejects the offer (he chooses option A), both players

\footnotetext{
${ }^{6}$ Anonymity as a key factor of deindividuation has been extensively studied in social psychology. The deindividuation theory of Festinger et al. (1952) predicts that the anonymity of individuals in a group may lower their sense of personal identity and reduce compliance with the group norm. In contrast, the social identity model of deindividuation (Reicher $e t$ $a l ., 1995)$ suggests that anonymity facilitates the alignment of the individual with the group's preferences.

${ }^{7}$ Fehr and Schmidt define utility as follows: $U_{i}=x_{i}-\frac{\alpha_{i}}{n-1} \sum_{k \neq i} \max \left(x_{k}-x_{i}, 0\right)-\frac{\beta_{i}}{n-1} \sum_{k \neq i} \max \left(x_{i}-x_{k}, 0\right)$, assuming that $0 \leq \beta_{i} \leq \alpha_{i}$ and $\beta_{i}<1$, with $\alpha$ representing the disadvantageous inequality aversion parameter and $\beta$ the advantageous inequality aversion parameter, and with $x_{i}$ and $x_{k}$ representing the payoffs of players $i$ and $k$, respectively. In a two-player game, utility is thus defined as $U_{i}\left(x_{i}, x_{j}\right)=x_{i}-\alpha_{i}\left(x_{j}-x_{i}\right)$ if $x_{i} \leq x_{j}$ and $U_{i}\left(x_{i}, x_{j}\right)=x_{i}-\beta_{i}\left(x_{i}-x_{j}\right)$ if $X_{i}>X_{j}$

${ }^{8}$ Brandts and Charness (2011) survey the literature to compare the strategy method and the direct-response method. A total of 16 out of the 29 comparisons show no difference, four find differences and nine find mixed evidence.
} 
earn zero. If the responder accepts the offer (he chooses option B), the share is implemented. The proposers' offers are restricted to multiples of 20, leading to 21 distributions from $(400,0),(380$, $20), \ldots$ to $(0,400)$. Subjects make their 21 decisions in each of the two roles sequentially on two separate screens to minimize interactions between the two decisions.

Table 1. The Ultimatum Game and the Modified Dictator Game

\begin{tabular}{|c|c|c|c|c|c|}
\hline \multirow{3}{*}{$\begin{array}{c}\text { Decision } \\
\text { problem }\end{array}$} & \multicolumn{3}{|c|}{ Ultimatum Game } & \multirow{2}{*}{\multicolumn{2}{|c|}{$\frac{\text { Modified Dictator Game }}{\text { Dictator's decision }}$}} \\
\hline & \multirow{2}{*}{$\begin{array}{l}\text { Proposer's } \\
\text { decision }\end{array}$} & \multicolumn{2}{|c|}{ Responder's decision } & & \\
\hline & & Option A & Option B & Option A & Option B \\
\hline 1 & $(400,0)$ & Reject & Accept & $(400,0)$ & $(0,0)$ \\
\hline 2 & $(380,20)$ & Reject & Accept & $(400,0)$ & $(20,20)$ \\
\hline 3 & $(360,40)$ & Reject & Accept & $(400,0)$ & $(40,40)$ \\
\hline 4 & $(340,60)$ & Reject & Accept & $(400,0)$ & $(60,60)$ \\
\hline 5 & $(320,80)$ & Reject & Accept & $(400,0)$ & $(80,80)$ \\
\hline 6 & $(300,100)$ & Reject & Accept & $(400,0)$ & $(100,100)$ \\
\hline 7 & $(280,120)$ & Reject & Accept & $(400,0)$ & $(120,120)$ \\
\hline 8 & $(260,140)$ & Reject & Accept & $(400,0)$ & $(140,140)$ \\
\hline 9 & $(240,160)$ & Reject & Accept & $(400,0)$ & $(160,160)$ \\
\hline 10 & $(220,180)$ & Reject & Accept & $(400,0)$ & $(180,180)$ \\
\hline 11 & $(200,200)$ & Reject & Accept & $(400,0)$ & $(200,200)$ \\
\hline 12 & $(180,220)$ & Reject & Accept & $(400,0)$ & $(220,220)$ \\
\hline 13 & $(160,240)$ & Reject & Accept & $(400,0)$ & $(240,240)$ \\
\hline 14 & $(140,260)$ & Reject & Accept & $(400,0)$ & $(260,260)$ \\
\hline 15 & $(120,280)$ & Reject & Accept & $(400,0)$ & $(280,280)$ \\
\hline 16 & $(100,300)$ & Reject & Accept & $(400,0)$ & $(300,300)$ \\
\hline 17 & $(80,320)$ & Reject & Accept & $(400,0)$ & $(320,320)$ \\
\hline 18 & $(60,340)$ & Reject & Accept & $(400,0)$ & $(340,340)$ \\
\hline 19 & $(40,360)$ & Reject & Accept & $(400,0)$ & $(360,360)$ \\
\hline 20 & $(20,380)$ & Reject & Accept & $(400,0)$ & $(380,380)$ \\
\hline 21 & $(0,400)$ & Reject & Accept & $(400,0)$ & $(400,400)$ \\
\hline
\end{tabular}

Note: The first numbers in parentheses display the proposer's payoffs, the second numbers the receivers' payoffs.

In the Modified Dictator Game (MDG, hereafter), the dictator also receives a pie of 400 points and she must decide how many of these points she is willing to pay to equalize payoffs between herself and the receiver. There are 21 decision problems with two options. The left option always pays 400 points to the dictator and nothing to the receiver. The right option gives equal payoffs to both players and varies from $(0,0),(20,20), \ldots$ to $(400,400)$. Each subject makes a choice in the role of a dictator. 
In both games, we impose the restriction of single switching between the two options in the 21 problems. ${ }^{9}$ Specifically, in the UG, responders choose the number of the decision problem from which they accept all of the proposer's offers; in the MDG, dictators select the number of the decision problem from which they always choose equal sharing. It was made clear to the subjects that they could switch from the first problem and that they were also allowed not to switch at all. This ability gives each responder in the UG a single minimum acceptable offer that determines the envy parameter, $\alpha$. In the MDG, this ability reveals the maximum amount that the dictator is willing to sacrifice to implement equal sharing, which allows us to estimate the guilt parameter, $\beta$. These parameters are calculated as in Blanco et al., using non-linear monotonic conversion. ${ }^{10}$

The actual role in each of these games was randomly assigned at the end of the session, and only one of the 21 decision problems in each game was randomly selected for payment.

\footnotetext{
${ }^{9}$ Imposing single switching is in contrast with Blanco et al. Of course, rational players with monotone preferences should switch only once from Option A to Option B because their payoff becomes larger in the UG for all decision problems beyond the switching point; similarly in the MDG, the egalitarian outcome is always cheaper beyond this point. However, approximately $15 \%$ of subjects switched several times in Blanco et al. Imposing single switching rules out inconsistent choices and facilitates team decision-making. The same procedure has been applied in the literature to elicit risk preferences and time consistency (see Tanaka et al., 2010).

${ }^{10}$ As explained by Blanco et al., to determine a near point estimate of $\alpha_{i}$ for each individual, we can suppose that $s_{i}{ }_{i}$ is the minimum offer responder $i$ is willing to accept and $s^{\prime}{ }_{i}-20$ is the highest offer that $i$ rejects. A responder is indifferent between accepting an offer $s_{i} \in\left[s_{i}^{\prime}-20, s_{i}\right]$ and rejecting it. Thus, $U_{i}\left(s_{i}, 400-s_{i}\right)=s_{i}-\alpha_{i}\left(400-s_{i}-s_{i}\right)=0$, which gives $\alpha_{i}=\frac{s_{1}}{\left[2\left(200-s_{1}\right)\right]}$.

Determining a near point estimate of $\beta_{i}$ for each individual requires identifying the decision $\left(x_{i}, x_{i}\right)$ for which the dictator in the MDG is indifferent between sharing equally and keeping her 400 points. If she switches to equal sharing at $\left(x_{i}^{\prime}, x_{i}^{\prime}\right)$, she prefers $(400,0)$ over $\left(x_{i}^{\prime}-20, x_{i}^{\prime}-20\right)$ but $\left(x_{i}^{\prime}, x_{i}^{\prime}\right)$ over $(400,0)$. Thus, she is indifferent between $(400,0)$ and $\left(\tilde{x}_{i}, \tilde{x}_{i}\right)$, where $\tilde{x}_{i} \in\left[x_{i}{ }^{\prime}-20, x_{i}{ }^{\prime}\right]$ and $x_{i} \in\{0, \ldots, 400\}$. So, $\beta_{i}$ is estimated from the equation $U_{i}(400,0)=U_{i}\left(\tilde{x}_{i}, \tilde{x}_{i}\right)$ iff $400-400 \beta_{i}=\tilde{x}_{i}$, which gives $\beta_{i}=1-\frac{\tilde{x}_{i}}{400}$.

We assume $S_{i}=S_{i}-10$ and $\tilde{x}_{i}=x_{i}{ }^{\prime}-10$. For the responders who accept only $s_{i}>200$ in the UG, we only know that $\alpha_{i} \geq 4.5$, and therefore we consider arbitrarily that $\alpha_{i}=4.5$, and if $s^{\prime}{ }_{i}=0$, we set $\alpha_{i}=0$. Similarly, we set $\beta_{i}=0$ for subjects who prefer $(400,0)$ to $(400,400)$ but who perhaps would have $\beta_{i}<0$, and we set $\beta_{i}=1$ for subjects who prefer $(0,0)$ over $(400,0)$ but who perhaps would have $\beta_{i}>1$ because we cannot observe a switching point.
} 
In addition, we used the Production Game (PG, hereafter) of Yang et al. (2012) ${ }^{11}$ to test the predictive power of the inequality aversion estimates from the UG and the MDG for individuals and teams. The PG involves two workers, A and B, who are in charge of departments 1 and 2, respectively. Each worker chooses an effort level (an integer between 0 and 100, multiple of 10) that determines the production of his department, $p_{i}$ :

$$
p_{i}\left(e_{i}\right)=4 e_{i}-e_{i}^{2} / 100, i=A, B
$$

The effort of each worker in his department conditions both his payoff and his co-worker's payoff. Indeed, the total income in this game is determined by four elements. (1) A's fixed salary, $s_{i}$, is 200 points for A and 0 points for B. (2) Bonus 1 depends on A's production in department 1: this production is equally divided between A and B. (3) Bonus 2 depends on B's production in department 2: this production is also equally shared between A and B. (4) Effort is costly: each unit of effort in one's department costs 2 points to A and 1 point to B. The total income is therefore equal to the sum of the basic salary and half of Bonuses 1 and 2 minus the cost of effort, that is,

$$
\pi_{i}\left(e_{A}, e_{B}\right)=s_{i}+\frac{1}{2} \sum_{j=A, B} p_{j}\left(e_{j}\right)-e_{i} c_{i}, i=A, B .
$$

Because worker A always earns more than B regardless of the combination of efforts, the prediction is that worker A's effort should depend positively on his degree of guilt, while the effort of worker B should depend negatively on his degree of envy.

Subjects must make two simultaneous effort decisions in the role of A and B, as indicated in Figure A1 in Appendix 2. For each decision, the subjects can use a calculator on their screen to explore the consequences of any possible combination of effort exerted by A and B before

\footnotetext{
${ }^{11}$ We are grateful to the authors for sharing their z-Tree code for the PG with us.
} 
validating their two effort choices. ${ }^{12}$ As before, the actual roles in the pairs are randomly assigned only at the end of the session.

\section{Inequality aversion in teams}

To elicit team inequality aversion, we paired teams of three individuals who play a collective version of the previously described Ultimatum and Modified Dictator Games. We also implemented a team version of the Production Game to study whether team inequality aversion elicited with the UG and the MDG has predictive value. We use the same Tables as for individual decisions. To hold the players' monetary incentives comparable across individual and team conditions, the payoffs achieved in the team games are paid to each team member. For example, if the selected decision in the DG pays 400 points to the dictator team and leaves nothing for the receiver team, each of the three dictator team members earns 400 points and each of the three receiver team members receives 0 . The actual role of a team in each game was randomly assigned at the end of the session, and one decision problem in each of the UG and the MDG was randomly selected for payment.

The unanimity of team members is required to form the team decision. ${ }^{13}$ All of the members of a team must agree on i) the offer proposed to the responder team in the UG; ii) the number of the decision problem from which the team accepts all of the proposer team's offers in the UG; iii) the number of the decision problem from which the dictator team always chooses equal sharing in the MDG; and iv) the efforts of working teams A and B in the PG. Precisely, in each game, the team members must simultaneously submit their individual proposal for the team decision. Once the three proposals have been submitted, they are displayed on the team members' screens. If they are not

\footnotetext{
${ }^{12}$ A subject's screen displays his effort level, the bonus from his department, his effort cost and his total income. The bonus from the other department cannot be displayed because it depends on the other worker's effort. The consequences of this other effort could be explored in the right panel of the screen.

${ }^{13}$ Many papers on group decisions impose unanimity (e.g., Sutter, 2005; Kocher and Sutter, 2005, 2007; Shupp and Williams, 2008; Luhan et al., 2009; Sutter et al., 2009). Some use the majority (Baker et al., 2008; Harrison et al., 2012) or the median (Bischoff and Krauskopf, 2013). Others allow for unrestricted deliberation (Cason and Mui, 1997; Bornstein et al., 2004; Bosman et al., 2006; Schupp and Williams, 2008; Ambrus et al., 2013).
} 
identical, a new round starts and each member must submit a new proposal. It is made clear that members are allowed to submit the same proposal as in the previous round. This procedure is repeated until all team members submit identical proposals. The number of rounds is unrestricted within the limit of 10 minutes for each team's decision. In case unanimity has not been reached after the 10 minutes have elapsed, it is common information that the computer selects one of the possible decisions at random.

One advantage of our design is that for each subject, we are able to observe his individual decision made in isolation, which should reveal his inner preference, his initial proposal in the team bargaining, and his final decision as aggregated in the team decision.

\subsection{Treatments and matching protocol}

The experiment consists of three main treatments using a between-subjects design. Each treatment includes five parts that allow us to make within-subject comparisons across parts. In all of the treatments, Parts 1 and 2 correspond to the one-shot UG and MDG played individually, whereas Parts 3, 4 and 5 differ across treatments.

The I-I (I for Individual) treatment involves only individual decision-making: Parts 3 and 4 replicate Parts 1 and 2 (UG and MDG) and Part 5 consists of the individual PG.

The I-AT (AT for Anonymous Team) treatment introduces collective decision-making in Parts 3 and 4 (UG and MDG) and in Part 5 (PG). Players do not know whom they are interacting with, and there is no possible identification of team members.

The I-NAT (NAT for Non-Anonymous Team) treatment is identical to the I-AT treatment with two exceptions. First, we lift anonymity within the team: at the beginning of Part 3, players are told that the three participants seated in the same row belong to the same team, with identification numbers I, II, and III assigned to the players seated at the left, middle and right of the row, 
respectively. Second, the number of the player appears next to his proposals so that teammates can trace the evolution of a player's proposals across rounds. In contrast, players receive no information on the composition of the team they are paired with and on the proposals made within the other team. This treatment is designed to measure whether less anonymity in social interactions affects guilt and envy.

We also conducted a reverse-order control treatment, denoted as the NAT-I treatment. Its content is similar to the I-NAT treatment, except that the appearance order of Parts 3 and 4 and Parts 1 and 2 is reversed. Comparing decisions in this treatment and in the other treatments indicates whether the sequence of tasks in either an individual or a team context matters. ${ }^{14}$ In particular, we can identify social influence or persuasion by studying whether decisions made in isolation after a team decision differ from those made before the team bargaining.

In each treatment, the appearance order of the UG and the MDG was randomized across sessions, but the appearance order of the two games was held constant in Parts 1 and 2 and in Parts 3 and 4 in the same session. A perfect stranger matching protocol rules out reciprocity and reputation building across parts. Each team was paired with a different team and each individual was paired with a different player across parts. In contrast, the composition of each team was kept constant across the parts with collective decisions.

Table 2 summarizes the key features of our experimental design.

\footnotetext{
${ }^{14}$ For example, Baker et al. (2008) conduct a three-stage individual-group-individual sequenced lottery-choice experiment and find that the individual decisions made in the first and the third stages differ. However, the effects of group decision-making and learning cannot be disentangled. To avoid this problem, we replace this three-phase process with three two-phase sequences (I-I, I-NAT and NAT-I).
} 
Table 2. Summary of the experimental design

\begin{tabular}{lccccc}
\hline Treatment & Part 1 & Part 2 & Part 3 & Part 4 & Part 5 \\
\hline I-I & Individual & Individual & Individual & Individual & Individual \\
& UG/MDG & MDG/UG & UG/MDG & MDG/UG & PG \\
I-AT & Individual & Individual & Team & Team MDG/UG & Team PG \\
& UG/MDG & MDG/UG & Anonymity & Anonymity & Anonymity \\
& Individual & Individual & Team & Team MDG/UG & Team PG \\
I-NAT & UG/MDG & MDG/UG & No anonymity & No anonymity & No anonymity \\
& Team & Team & Individual & Individual & Team PG \\
\multirow{2}{*}{ NAT-I } & UG/MDG & MDG/UG & UG/MDG & MDG/UG & No anonymity \\
& No anonymity & No anonymity & and & &
\end{tabular}

Note: UG for Ultimatum Game, MDG for Modified Dictator Game, and PG for Production Game.

\subsection{Procedures}

The experiment was conducted at the laboratory of Beijing Normal University. A total of 336 volunteers were recruited via announcements on the bulletin board system and in teaching and accommodation buildings of local universities. These were split into 24 subjects participating in each of 14 sessions ( 2 sessions with I-I and 4 with each of the I-AT, I-NAT and NAT-I treatments). In total, we obtained 48 individual observations for the I-I treatment and 32 team observations (96 subjects) for each of the I-AT, I-NAT and NAT-I treatments. Due to an inability to reach unanimity, we lost a few team observations either in the role of the dictator in the MDG ( 1 in both I-AT and NAT-I) or in the role of the proposer in the UG (4 in I-AT and 2 in NAT-I).

The experiment was computerized using z-Tree (Fischbacher, 2007). Upon arrival, the participants were assigned randomly to a computer terminal. Each part was introduced sequentially after completion of the previous one. Instructions for each part were not distributed until the beginning of that part and questions were answered in private (see Appendix 1). Subjects were given no information about the number of parts and they received no feedback on the outcome of any part until the end of the entire experiment.

Sessions lasted approximately 90 minutes. Participants received in cash the sum of their earnings for all parts from an assistant who was not aware of the content of the experiment. This was 
common information offered in the instructions. Participants earned on average 82.70 Yuan (about \$13.65), including a 10-Yuan show-up fee.

\section{RESULTS}

First, we report descriptive statistics on the envy (aversion to disadvantageous inequality, $\alpha$ ) and guilt (aversion to advantageous inequality, $\beta$ ) parameters in individuals and teams. Second, we compare inequality aversion for individuals and teams across treatments. Third, we explore the process that leads to unanimous team decisions. Last, we test whether the guilt and envy parameters predict behavior in the Production Game.

\subsection{Guilt and envy in individuals and teams}

Table 3 displays for each treatment the distribution of the two parameters using the same intervals as Fehr and Schmidt (1999) and Blanco et al. (2011) based on the individual decisions, the individual initial proposals in team decision-making, and the team decisions.

At the extreme ends of the distribution, we find $14 \%$ of subjects with $\alpha=0,10 \%$ of subjects with $\alpha \geq$ $4.5,8 \%$ of subjects with $\beta=0$ and $5 \%$ of subjects with $\beta=1$.

Table 3. Distribution of the $\alpha$ and $\beta$ parameters for individual and team decisions, by intervals and treatment

\begin{tabular}{|c|c|c|c|c|c|c|c|c|}
\hline & & \multicolumn{4}{|c|}{ Envy parameter $(\alpha)$} & \multicolumn{3}{|c|}{ Guilt parameter $(\beta)$} \\
\hline & & $\alpha<0.4$ & $0.4 \leq \alpha<0.92$ & $0.92 \leq \alpha<4.5$ & $4.5 \leq \alpha$ & $\beta<0.235$ & $0.235 \leq \beta<0.5$ & $0.5 \leq \beta$ \\
\hline \multirow{2}{*}{\multicolumn{2}{|c|}{$\begin{array}{l}\text { Fehr and Schmidt (1999) } \\
\text { Blanco et al. (2011) }\end{array}$}} & $30 \%$ & $30 \%$ & $30 \%$ & $10 \%$ & $30 \%$ & $30 \%$ & $40 \%$ \\
\hline & & $31 \%$ & $33 \%$ & $23 \%$ & $13 \%$ & $29 \%$ & $15 \%$ & $56 \%$ \\
\hline \multicolumn{9}{|c|}{ Our data } \\
\hline $\begin{array}{l}\text { Individual } \\
\text { decisions }\end{array}$ & $\begin{array}{l}\text { All } \\
\text { treatments }\end{array}$ & $35 \%$ & $24 \%$ & $31 \%$ & $10 \%$ & $23 \%$ & $23 \%$ & $54 \%$ \\
\hline \multirow{3}{*}{$\begin{array}{l}\text { Individual } \\
\text { initial } \\
\text { proposals }\end{array}$} & I-AT & $26 \%$ & $18 \%$ & $37 \%$ & $19 \%$ & $16 \%$ & $18 \%$ & $66 \%$ \\
\hline & I-NAT & $25 \%$ & $19 \%$ & $45 \%$ & $11 \%$ & $15 \%$ & $20 \%$ & $66 \%$ \\
\hline & NAT-I & $30 \%$ & $18 \%$ & $37 \%$ & $16 \%$ & $27 \%$ & $32 \%$ & $41 \%$ \\
\hline \multirow{3}{*}{$\begin{array}{l}\text { Team } \\
\text { decisions }\end{array}$} & I-AT & $21 \%$ & $29 \%$ & $39 \%$ & $11 \%$ & $13 \%$ & $19 \%$ & $68 \%$ \\
\hline & I-NAT & $22 \%$ & $25 \%$ & $47 \%$ & $6 \%$ & $16 \%$ & $25 \%$ & $59 \%$ \\
\hline & NAT-I & $33 \%$ & $23 \%$ & $40 \%$ & $3 \%$ & $29 \%$ & $32 \%$ & $39 \%$ \\
\hline
\end{tabular}


Using point estimates, Mann-Whitney rank-sum tests (M-W hereafter) ${ }^{15}$ indicate no significant difference between the values of $\alpha$ and $\beta$ calculated from individual decisions in our experiment and those reported in Blanco et al. (2011) ( $p=0.594$ for $\alpha$ and $p=0.878$ for $\beta) .{ }^{16,17}$ Kolmogorov-Smirnov tests indicate that the distributions of each parameter in the two samples are similar $(p=0.234$ for $\alpha$ and $p=0.562$ for $\beta$ ). Table 4 reports the mean values of the guilt and envy point estimates based on the same three types of decisions, by treatment.

Table 4 reveals an inverted U-shaped trend of variation in both $\alpha$ and $\beta$ from individual decisions to individual initial proposals, and from initial proposals to team decisions in all treatments with team decision-making, regardless of the order of decisions. Indeed, the mean values of $\alpha$ and $\beta$ are always higher in the individual initial proposals compared to both the individual and the team decisions. Individuals appear to make on average more inequality-averse initial proposals in teams than when they decide in isolation.

\footnotetext{
${ }^{15}$ All the reported non-parametric tests are two-tailed, unless specified otherwise. Each individual gives one independent observation in the individual decisions and initial proposals, while each team gives one independent observation for the team decisions. It should be noted that considering $s_{i}=s_{i}{ }^{\prime}-10$ and $\tilde{x}_{i}=x_{i}^{\prime}-10$ in the calculation of the envy and guilt parameters is an approximation that does not impact the results of the non-parametric statistics because they are based on ordinal rankings (see Blanco et al., 2011).

${ }^{16}$ In the UG, the mean individual offer is $40 \%$ of the pie (the same in teams) and $32.74 \%$ of the subjects $(33.03 \%$ of teams) chose the equal split. In Blanco et al., these percentages are respectively $40 \%$ and $48 \%$. The median and mean of both the individual and team acceptance threshold correspond to decision problem \#6 $(300,100)$. In the MDG played in isolation, the average switching point is at decision problem \#12 (220-220) (the same in teams) and 32.74\% of the subjects $(27.27 \%$ of teams) switch to the egalitarian option before decision problem \#10. In Blanco et al., where subjects must share a pie of $£ 20$, the mean was also decision problem \#12 (£11-£11 vs. $£ 20-£ 0$ ), but $43 \%$ of the subjects switched in the range (£0-£0) to (£9-£9). This comparison indicates some but no dramatic differences between individual and team decisions in our experiment and between individual decisions in our data and those reported in Blanco et al.

${ }^{17}$ In the absence of individual data to compare with Fehr and Schmidt (1999), we conducted Chi-squared tests like Blanco et al. with the aggregate data for the distributional percentages in the different categories. We find no significant difference between the distributions of $\alpha$ and $\beta$ in our experiment and those reported in Fehr and Schmidt (1999) $(p=0.785$ for $\alpha$ and $p=0.140$ for $\beta)$.
} 
Table 4. Mean values of the $\alpha$ and $\beta$ parameters for individual and team decisions, by treatment

\begin{tabular}{lccccccccc}
\hline Treatments & \multicolumn{3}{c}{ Individual decisions } & \multicolumn{3}{c}{ Individual initial proposals } & \multicolumn{3}{c}{ Team decisions } \\
\cline { 2 - 10 } & Mean & S.D. & Obs. & Mean & S.D. & Obs. & Mean & S.D. & Obs. \\
\hline Envy parameter $(\alpha)$ & & & & & & & & & \\
I-I & 1.07 & 1.43 & 48 & - & - & - & - & - & - \\
I-AT & 1.29 & 1.53 & 84 & 1.68 & 1.67 & 84 & 1.34 & 1.43 & 28 \\
I-NAT & 1.04 & 1.29 & 96 & 1.49 & 1.46 & 96 & 1.29 & 1.26 & 32 \\
NAT-I & 1.10 & 1.40 & 90 & 1.47 & 1.59 & 90 & 1.12 & 1.27 & 30 \\
\hline Guilt parameter $(\beta)$ & & & & & & & & & - \\
I-I & 0.45 & 0.28 & 48 & - & - & - & - & - & 31 \\
I-AT & 0.51 & 0.29 & 93 & 0.54 & 0.28 & 93 & 0.51 & 0.20 & 32 \\
I-NAT & 0.45 & 0.27 & 96 & 0.53 & 0.26 & 96 & 0.50 & 0.21 & 32 \\
NAT-I & 0.36 & 0.29 & 93 & 0.39 & 0.24 & 93 & 0.35 & 0.22 & 31 \\
\hline
\end{tabular}

Note: S.D. stands for standard deviations. The number of team observations is different for $\alpha$ and $\beta$ because the number of teams reaching unanimity differs in the UG and the MDG.

The joint distributions of the $\alpha$ and $\beta$ parameters in each treatment and for each type of decision are displayed in Figure A2 in Appendix 2. Spearman correlation coefficients indicate that $\alpha$ and $\beta$ are not correlated in either individual decisions, initial proposals or team decisions in any treatment ( $p>0.100$ in all cases). This result is consistent with Blanco et al. but in contrast with Fehr and Schmidt's assumption. Finally, when pooling treatments together, we find that $40 \%$ of the subjects violate Fehr and Schmidt's assumption that $\alpha \geq \beta$ when making individual decisions. This violation occurs for $33 \%$ of the team decisions in I-AT, $34 \%$ in I-NAT and $28 \%$ in NAT-I. Wilcoxon signed rank tests $(\mathrm{W}$, hereafter) on the difference in means for each treatment indicate that teams are not significantly more or less likely than individuals to have $\alpha \geq \beta(p>0.100)$.

We state our first results as follows:

Result 1: Despite exposure to different cultural, political and economic institutions, our subjects in China exhibit levels of advantageous and disadvantageous inequality aversion similar to the European subjects in previous experiments.

Result 2: There is an inverted U-shaped trend in both $\alpha$ and $\beta$ from individual decisions to individual initial proposals within teams and to team decisions.

We next turn to a statistical analysis of the differences across subjects and treatments. 


\subsection{Within- and between-subject comparisons}

\section{Within-subject comparisons in each treatment}

The I-I treatment shows no significant difference in the values of $\alpha$ (W tests, $p=0.453)$ and $\beta$ $(p=0.929)$ between the two sequences of individual decisions. In the other treatments, the only significant difference between individual and team decisions is found in I-NAT for the guilt parameter $\beta$, which is higher in teams $(p=0.059)$. These results differ from the common finding in the literature stating that teams behave more selfishly than individuals. This result does not mean, however, that team decisions are simply the mean of individuals' preferences. Indeed, individual initial proposals differ from both decisions made in isolation and from the final team decision.

Comparing the individual decisions made in isolation and the individual initial proposals in teams reveals significant negative differences for both parameters. Regarding $\alpha$, Wilcoxon signed tests indicate $p$-values of 0.005 in I-AT, 0.001 in I-NAT and 0.019 in NAT-I. The respective $p$ values for $\beta$ are $0.033,0.001$ and 0.588 . Thus, in most cases, the initial proposals in teams reveal more envy and guilt than the individual decisions made in isolation. ${ }^{18}$ This result can be attributed to two reasons. Inequality averse individuals may anticipate that other team members are more selfish (recall that subjects receive no information about the preferences of their team members). Thus, inequality averse individuals may strategically submit more inequality averse proposals to compensate for the expected more selfish decisions of others, whereas selfish subjects can adjust their proposals toward only one direction. Alternatively, behavior may be driven by social image concerns because proposals are shown to team members. If the second interpretation is correct, then we should observe significantly larger differences between individual decisions and initial proposals in I-NAT and I-AT. However, Chi-squared tests reject the difference between the two coefficients

\footnotetext{
${ }^{18}$ This result is largely confirmed by the random-effects interval regressions and Tobit regressions reported in Table A1 in Appendix 2 in which we study the sensitivity of $\alpha$ and $\beta$ to the type of decision by treatment. Detailed results from the post-regression tests are shown in Table A2.
} 
for both $\alpha(p=0.729)$ and $\beta(p=0.148)$. This result provides stronger support to the strategic interpretation.

Finally, comparing the individual initial proposals and the final team decisions reveals significant positive differences for $\alpha$ in I-AT $(p=0.010)$ and NAT-I $(p=0.023)$, but not in I-NAT $(p=0.158)$. In most treatments, the aggregation process moves teams towards less envious decisions. In contrast, aggregation does not significantly modify the guilt parameter $\beta$ ( $p=0.196$ in I-AT, 0.282 in I-NAT and 0.394 in NAT-I).

\section{Between-subject comparisons across treatments}

We can first rule out the possibility that the differences between treatments are due to sample specificities. Pairwise comparisons show no significant difference in the guilt and envy parameters derived from individual decisions. ${ }^{19}$ There is no significant difference either when comparing the second set of individual decisions in I-I and the team decisions in I-AT (M-W, $p=0.142$ for $\alpha, 0.266$ for $\beta$ ) and I-NAT ( $p=0.110$ for $\alpha, 0.398$ for $\beta$ ). In contrast and consistent with the within-subject analysis, M-W tests indicate significant differences between the second set of individual decisions in I-I and the individual initial proposals in I-AT ( $p=0.036$ for $\alpha, 0.068$ for $\beta$ ) and I-NAT $(p=0.032$ for $\alpha, 0.080$ for $\beta$ ). Because we find no significant difference between I-AT and I-NAT as regards both the individual initial proposals (M-W tests, $p=0.719$ for $\alpha, 0.834$ for $\beta$ ) and the team decisions ( $p=0.940$ for $\alpha, 0.754$ for $\beta$ ), it is unlikely that social image motivates the higher inequality aversion in initial proposals within teams.

Finally, we compare the I-NAT and the NAT-I treatments to explore order effects. Starting a session with team decision-making reduces people's guilt in initial proposals and in team decisions

\footnotetext{
${ }^{19} \mathrm{M}-\mathrm{W}$ tests give the following $p$-values for $\alpha$ : 0.673 for I-I $v s$. I-AT, 0.841 for I-I $v s$. I-NAT, and 0.650 for I-AT $v s$. INAT. The respective values for $\beta$ are $0.277,0.942$, and 0.221 . Using instead Fisher's exact tests for categorical outcomes gives the same qualitative conclusions. Kruskal-Wallis tests for I-I $v s$. I-AT $v s$. I-NAT indicate $p=0.867$ for $\alpha$ and 0.386 for $\beta$.
} 
(M-W tests, $p<0.001)$. Guilt in individual decisions is also lower when individual decisions follow team decisions $(p=0.031)$ than when they precede them. We cannot, however, conclude with certainty that this result stems from social information or persuasion when others' preferences are revealed by the aggregation process. Indeed, guilt in initial proposals in NAT-I is also lower than that in individual decisions in the treatments in which team decision-making follows decisions made in isolation. In contrast, the degree of envy revealed by individual decisions, initial proposals and team decisions is not affected by the order of the decisions ( $p=0.990,0.613$, and 0.455 , respectively).

An econometric analysis of envy and guilt in individuals and teams

Table 5 reports Tobit regressions (because data are censored) that investigate the determinants of the envy parameter $\alpha$ (models (1) to (4)) and the guilt parameter $\beta$ (models (5) to (8)) as determined by the individual decisions from all treatments, by the individual initial proposals and by the team decisions in the I-AT, I-NAT and NAT-I treatments. Models (4) and (8) pool the data from the individual decisions and individual initial proposals in teams and include an independent dummy variable for individual decision-making. ${ }^{20}$

${ }^{20} \mathrm{We}$ also estimated interval regressions (see Table A3 in Appendix), which provide qualitatively similar results. 
Table 5. Tobit regressions of the envy and guilt parameters, by treatment

\begin{tabular}{|c|c|c|c|c|c|c|c|c|}
\hline & \multicolumn{4}{|c|}{ Envy parameter $(\alpha)$} & \multicolumn{4}{|c|}{ Guilt parameter $(\beta)$} \\
\hline & $\begin{array}{l}\text { Indiv. } \\
\text { decision } \\
\text { (1) }\end{array}$ & $\begin{array}{c}\text { Ind. initial } \\
\text { proposal } \\
\text { (2) }\end{array}$ & $\begin{array}{c}\text { Team } \\
\text { decision } \\
(3)\end{array}$ & $\begin{array}{l}\text { Pooled indiv. } \\
\text { decision \& } \\
\text { indiv. initial } \\
\text { proposal (4) }\end{array}$ & $\begin{array}{l}\text { Indiv. } \\
\text { decision } \\
(5)\end{array}$ & $\begin{array}{c}\text { Ind. initial } \\
\text { proposal } \\
\text { (6) }\end{array}$ & $\begin{array}{c}\text { Team } \\
\text { decision } \\
(7)\end{array}$ & $\begin{array}{c}\text { Pooled indiv. } \\
\text { decision \& } \\
\text { indiv. initial } \\
\text { proposal (8) }\end{array}$ \\
\hline $\begin{array}{l}\text { Team decision first } \\
\text { (NAT-I treatment) }\end{array}$ & $\begin{array}{c}0.024 \\
(0.158)\end{array}$ & $\begin{array}{l}-0.103 \\
(0.165)\end{array}$ & $\begin{array}{l}-0.158 \\
(0.221)\end{array}$ & $\begin{array}{l}-0.145 \\
(0.186)\end{array}$ & $\begin{array}{c}-0.120 * * * \\
(0.034)\end{array}$ & $\begin{array}{c}-0.069 * * * \\
(0.027)\end{array}$ & $\begin{array}{c}-0.088 * * \\
(0.039)\end{array}$ & $\begin{array}{c}-0.152 * * * \\
(0.033)\end{array}$ \\
\hline Non-anonymity & - & $\begin{array}{c}0.032 \\
(0.171)\end{array}$ & $\begin{array}{c}0.230 \\
(0.399)\end{array}$ & - & - & $\begin{array}{c}0.004 \\
(0.027)\end{array}$ & $\begin{array}{c}0.060 \\
(0.065)\end{array}$ & - \\
\hline $\begin{array}{l}\text { Individual decision- } \\
\text { making }\end{array}$ & - & - & - & $\begin{array}{l}-0.435^{*} \\
(0.232)\end{array}$ & - & - & - & $\begin{array}{l}-0.080 * \\
(0.042)\end{array}$ \\
\hline $\begin{array}{l}\text { Number of males in the } \\
\text { team }\end{array}$ & - & - & $\begin{array}{l}0.150 \\
(0.225)\end{array}$ & - & - & - & $\begin{array}{l}-0.016 \\
(0.035)\end{array}$ & - \\
\hline $\begin{array}{l}\text { Number of males in the } \\
\text { team } * \text { Non-anonymity }\end{array}$ & - & - & $\begin{array}{l}-0.056 \\
(0.268)\end{array}$ & - & - & - & $\begin{array}{l}-0.023 \\
(0.042)\end{array}$ & - \\
\hline$\alpha$ in individual decision & - & $\begin{array}{c}0.644 * * * \\
(0.036)\end{array}$ & - & - & - & - & - & - \\
\hline$\beta$ in individual decision & - & - & - & - & - & $\begin{array}{c}0.635^{* * * *} \\
(0.032)\end{array}$ & - & - \\
\hline $\begin{array}{l}\text { Team mean } \alpha \text { in } \\
\text { individual decision }\end{array}$ & - & - & $\begin{array}{c}0.817 * * * \\
(0.086)\end{array}$ & - & - & - & - & - \\
\hline $\begin{array}{l}\text { Team mean } \beta \text { in } \\
\text { individual decision }\end{array}$ & - & - & - & - & - & - & $\begin{array}{c}0.831 * * * \\
(0.085)\end{array}$ & - \\
\hline Male & $\begin{array}{l}-0.004 \\
(0.152)\end{array}$ & $\begin{array}{c}0.202 \\
(0.144)\end{array}$ & - & $\begin{array}{c}0.119 \\
(0.171)\end{array}$ & $\begin{array}{l}-0.059 * \\
(0.033)\end{array}$ & $\begin{array}{l}-0.032 \\
(0.023)\end{array}$ & - & $\begin{array}{c}-0.063 * * \\
(0.031)\end{array}$ \\
\hline Rural register & $\begin{array}{l}-0.160 \\
(0.159)\end{array}$ & $\begin{array}{l}0.073 \\
(0.154)\end{array}$ & - & $\begin{array}{l}-0.052 \\
(0.180)\end{array}$ & $\begin{array}{c}0.038 \\
(0.034)\end{array}$ & $\begin{array}{c}0.072 * * * \\
(0.024)\end{array}$ & - & $\begin{array}{l}0.078 * * \\
(0.032)\end{array}$ \\
\hline $\begin{array}{l}\text { Number of close } \\
\text { friends }\end{array}$ & $\begin{array}{c}0.029 \\
(0.031)\end{array}$ & $\begin{array}{c}0.050 \\
(0.030)\end{array}$ & - & $\begin{array}{l}0.063^{*} \\
(0.035)\end{array}$ & $\begin{array}{c}0.015 * * \\
(0.007)\end{array}$ & $\begin{array}{c}0.008 \\
(0.005)\end{array}$ & - & $\begin{array}{c}0.016^{* *} \\
(0.006)\end{array}$ \\
\hline $\begin{array}{l}\text { Acquaintances in the } \\
\text { session }\end{array}$ & $\begin{array}{l}-0.090 \\
(0.155)\end{array}$ & $\begin{array}{l}-0.174 \\
(0.148)\end{array}$ & - & $\begin{array}{l}-0.279 \\
(0.175)\end{array}$ & $\begin{array}{l}-0.035 \\
(0.034)\end{array}$ & $\begin{array}{l}0.044^{*} \\
(0.023)\end{array}$ & - & $\begin{array}{c}0.012 \\
(0.032)\end{array}$ \\
\hline Boarding school & $\begin{array}{c}0.184 \\
(0.167)\end{array}$ & $\begin{array}{c}0.175 \\
(0.158)\end{array}$ & - & $\begin{array}{l}0.360 * \\
(0.188)\end{array}$ & $\begin{array}{c}0.021 \\
(0.037)\end{array}$ & $\begin{array}{c}0.018 \\
(0.025)\end{array}$ & - & $\begin{array}{c}0.042 \\
(0.034)\end{array}$ \\
\hline Other controls & Yes & Yes & No & Yes & Yes & Yes & No & Yes \\
\hline Observations & 318 & 270 & 90 & 318 & 330 & 282 & 94 & 330 \\
\hline Chi-squared test & 0.976 & 0.000 & 0.000 & 0.249 & 0.095 & 0.000 & 0.000 & 0.000 \\
\hline Log-likelihood & -564.107 & -427.932 & -129.671 & -582.510 & -125.663 & 34.909 & 35.454 & -87.571 \\
\hline
\end{tabular}

Notes: Marginal effects are reported and standard errors are in parentheses. *** indicates significance at the 0.01 level, ** at the 0.05 level, * at the 0.10 level. The other control variables include age, Han ethnicity, number of siblings, importance of social image, having already participated in an experiment, occupational activity while studying, being a member of the Communist party, studying economics, years of education, family size, number of siblings, income. 
The independent variables include a dummy variable to control for order effects between individual and team decision-making and a dummy variable to capture the influence of anonymity (except in the regressions on individual decisions). In the regressions on initial proposals, we include the respective point estimates of $\alpha$ (model (2)) and $\beta$ (model (5)) from individual decisions. In the regressions on team decisions, we include the respective mean value of $\alpha$ (model (3)) and $\beta$ (model (6)), as determined by the three teammates' individual decisions. We control for the gender composition of the team and interact this variable with the nonanonymity of the proposals. Finally, except for the regressions of the team decisions, we control for various demographic variables detailed below in Table 5, and we only report those that reach significance.

Table 5 confirms that individuals express more guilt and envy in their initial proposals within teams than when they decide in isolation (see models (4) and (8)). Naturally, more inequality aversion in individuals increases the pro-sociality of teams (see models (3) and (7)). Table 5 also reveals that anonymity within teams drives neither guilt nor envy. $\beta$ is lower when team decisions are made at the beginning of the experiment rather than later and when decisions made in isolation follow team decision-making. Finally, only a few demographic variables are significant. In particular, males express less guilt in individual decisions than females, whereas being a rural resident, attending a boarding school (meaning living in a dormitory) prior to entering university, having acquaintances in the session and more close friends all increase advantageous inequality aversion.

This analysis is summarized in the following results.

Result 3: The envy $(\alpha)$ and guilt $(\beta)$ parameters are similar for individual and team decisions.

Result 4: Individual initial proposals in teams reveal more guilt and envy than individual decisions made in isolation. This result is driven by strategic reasoning in the absence of information about others' preferences rather than by social image or social desirability. 


\subsection{Aggregation of individual choices in teams}

We now explore the aggregation of preferences in teams by means of two measures. The first measure is the number of proposal rounds needed to reach unanimity, which captures the tension in the team. The second measure is the convergence speed from an individual's initial proposal to the team decision, which describes how fast the individual proposals were aggregated into a team decision. The speed is given by the mean absolute distance (described by the number of decision problem) between an individual's initial proposal and the team decision divided by the number of rounds. A high value for this variable means a quick adjustment between more divergent decisions. We exclude four teams for which the initial proposals were already unanimous and eight teams that did not reach unanimity.

When we pool the three team treatments, it takes on average 4.44 rounds (S.D.=3.77) to converge to a team decision on the acceptance threshold in the UG and 4.14 rounds $($ S.D. $=2.11$ ) to converge to the dictator's decision in the MDG. ${ }^{21}$ These values do not differ significantly (W test, $p=0.327$ ). The mean convergence speed is 0.89 switching point per round in the UG (S.D.=1.49) and $1.37($ S.D. $=2.07)$ in the MDG. The difference is significant $(p<0.001)$ : dictators adjust more quickly than responders in the UG, suggesting that guilt is a weaker preference than envy. Comparing the I-AT and I-NAT treatments reveals no significant difference based on either the number of rounds or the convergence speed on the responders' acceptance threshold in the UG (W tests, $p=0.85$ and 0.91 , respectively) or the dictators' decision ( $p=0.29$ and 0.50 , respectively).

Table 6 reports four regressions in which the dependent variable is either the number of rounds until convergence (Tobit models (1) and (3)) ${ }^{22}$ or the convergence speed at the team level

\footnotetext{
${ }^{21}$ For the team acceptance decision in the UG, the number of rounds is 4.74 in I-AT, 4.19 in I-NAT and 4.44 in NAT-I, and the convergence speed is respectively $1.03,0.81$ and 0.85 . For the team dictator decisions, the number of rounds is 3.68 in I-AT, 4.13 in I-NAT and 4.61 in NAT-I, and the convergence speed is respectively $1.51,1.41$ and 1.18 .

${ }^{22}$ Using negative binomial count data models instead of the Tobit models delivers the same qualitative results.
} 
(OLS models (2) and (4)). Models (1) and (2) address the responder team's acceptance threshold in the UG and models (3) and (4) address the dictator team's decisions in the MDG. The independent variables include the mean, variance and skewness of the three individual initial proposals in the team. They also include controls for the order of the conditions (equal to 1 for NAT-I and 0 for the other treatments), the non-anonymity of proposals, the number of males in the team and a variable interacting the last two variables.

Table 6. Determinants of the number of proposal rounds and convergence speed in team decisions

\begin{tabular}{|c|c|c|c|c|}
\hline \multirow[b]{2}{*}{ Variables } & \multicolumn{2}{|c|}{ Envy parameter $(\alpha)$} & \multicolumn{2}{|c|}{ Guilt parameter $(\beta))$} \\
\hline & $\begin{array}{l}\text { Number of } \\
\text { proposal } \\
\text { rounds (1) }\end{array}$ & $\begin{array}{l}\text { Convergence } \\
\text { speed (2) }\end{array}$ & $\begin{array}{c}\text { Number of } \\
\text { proposal rounds } \\
\text { (3) }\end{array}$ & $\begin{array}{c}\text { Convergence } \\
\text { speed (4) }\end{array}$ \\
\hline Mean of initial proposals & $\begin{array}{l}-0.155 \\
(0.159)\end{array}$ & $\begin{array}{l}-0.011 \\
(0.031)\end{array}$ & $\begin{array}{l}0.114^{*} \\
(0.062)\end{array}$ & $\begin{array}{l}-0.058 * \\
(0.030)\end{array}$ \\
\hline $\begin{array}{l}\text { Variance of initial } \\
\text { proposals }\end{array}$ & $\begin{array}{c}0.077 * * * \\
(0.029)\end{array}$ & $\begin{array}{c}0.039 * * * \\
(0.006)\end{array}$ & $\begin{array}{c}0.015 * * \\
(0.007)\end{array}$ & $\begin{array}{c}0.022 * * * \\
(0.003)\end{array}$ \\
\hline $\begin{array}{l}\text { Skewness of initial } \\
\text { proposals }\end{array}$ & $\begin{array}{c}-1.407 * * * \\
(0.610)\end{array}$ & $\begin{array}{c}0.102 \\
(0.115)\end{array}$ & $\begin{array}{c}0.405 \\
(0.320)\end{array}$ & $\begin{array}{l}-0.005 \\
(0.154)\end{array}$ \\
\hline Order of conditions & $\begin{array}{c}0.445 \\
(0.802)\end{array}$ & $\begin{array}{l}-0.033 \\
(0.158)\end{array}$ & $\begin{array}{c}0.301 \\
(0.485)\end{array}$ & $\begin{array}{l}-0.040 \\
(0.236)\end{array}$ \\
\hline Non-anonymity & $\begin{array}{l}-1.894 \\
(1.387)\end{array}$ & $\begin{array}{c}0.117 \\
(0.271)\end{array}$ & $\begin{array}{l}1.770 * * \\
(0.794)\end{array}$ & $\begin{array}{l}-0.273 \\
(0.378)\end{array}$ \\
\hline $\begin{array}{l}\text { Number of males in the } \\
\text { team }\end{array}$ & $\begin{array}{l}-0.531 \\
(0.803)\end{array}$ & $\begin{array}{l}-0.008 \\
(0.153)\end{array}$ & $\begin{array}{l}1.260 * * * \\
(0.413)\end{array}$ & $\begin{array}{l}-0.308 \\
(0.198)\end{array}$ \\
\hline $\begin{array}{l}\text { Number of males in the } \\
\text { team* Non-anonymity }\end{array}$ & $\begin{array}{c}1.178 \\
(0.945)\end{array}$ & $\begin{array}{l}-0.214 \\
(0.183)\end{array}$ & $\begin{array}{c}-1.106 * * \\
(0.509)\end{array}$ & $\begin{array}{c}0.190 \\
(0.244)\end{array}$ \\
\hline Constant & - & $\begin{array}{c}0.613 * * \\
(0.301)\end{array}$ & - & $\begin{array}{c}1.775 * * * \\
(0.433)\end{array}$ \\
\hline Observations & 86 & 86 & 94 & 94 \\
\hline Left-censored obs. & 29 & - & 16 & - \\
\hline Chi-squared test & 0.014 & - & 0.002 & - \\
\hline F-test & - & $3.30 \mathrm{e}-07$ & - & $3.23 \mathrm{e}-07$ \\
\hline Pseudo- $\mathrm{R}^{2} / \mathrm{R}^{2}$ & 0.045 & 0.415 & 0.058 & 0.386 \\
\hline Log-Likelihood & -187.579 & - & -184.648 & - \\
\hline
\end{tabular}

Notes: The regressions include only teams that reached unanimity with at least two rounds of proposals. Models (1) and (3) are Tobit regressions and Models (2) and (4) are OLS regressions. Marginal effects ar, reported and standard errors are in parentheses. *** indicates significance at the 0.01 level, ** at the 0.05 level, * at the 0.10 level.

Table 6 reveals that a higher variance in the initial proposals increases both the number of rounds needed to reach unanimity and the convergence speed in both games. The skewness of the initial proposals reduces the number of rounds for convergence but only for the envy parameter. Higher mean initial proposals (i.e., lower guilt) marginally increase the number of 
rounds and decrease the convergence speed of the dictators' decisions. Table 6 also shows that abandoning anonymity increases the number of rounds needed to converge to the dictator choice. Because initial proposals were not higher in this condition, this result suggests that people are less prepared to make concessions when their choices are made visible to others, which supports the deindividuation theory of anonymity of Reicher et al. (1995). This effect is primarily driven by females, as it is largely reduced when the team includes more males. In contrast, when decisions are anonymous, having more males in a team increases the number of rounds.

Finally, we study who, among the selfish or the inequality averse subjects, are converging more rapidly to the team decision. In each team, we classify the players based on the median of the initial proposals, and we calculate for each player the number of rounds until this player proposes the team decision. We find that, on average, the median member needs 1.48 and 0.87 fewer rounds to reach the team decision than the player whose initial proposal is the least inequality averse in the team for the $\alpha$ and $\beta$ parameters, respectively (M-W tests, $p<0.001$ in both cases). He also needs, respectively, 1.02 and 0.62 fewer rounds than the player whose initial proposal is the most inequality averse ( $p<0.001$ in both cases). This result indicates that team decisions are driven by the median players, with the more extreme players in terms of inequality aversion neutralizing each other. We also consider the mean absolute distance between the initial proposal and the team decision. This distance is significantly smaller for the median player ( 0.398 for $\alpha$ and 0.048 for $\beta$ ) than for the player who made the least inequality averse initial proposal in the team ( 0.940 for $\alpha$ and 0.235 for $\beta$ ) or for the player who made the most inequality averse proposal (1.828 for $\alpha$ and 0.273 for $\beta$ ) ( $p<0.001$ in all comparison tests). This result indicates that members with a higher degree of inequality aversion make more concessions than the others, possibly because we have seen that they tend to inflate the inequality aversion of their initial proposals compared to their individual decisions. Finally, the move toward more selfish team decisions can be partly explained by the fact that median team members make on average 
less inequality averse initial proposals than the mean, at least for the $\alpha$ parameter (mean difference $=0.110, p=0.064)$ if not for $\beta$ (mean difference $=-0.007, p=0.401)$. These results are consistent with those of Ambrus et al. (2013).

This analysis supports the following results.

Result 5: A higher heterogeneity of team members' preferences in both games slows down the convergence to unanimity, while anonymity accelerates the convergence for the dictator team choice.

Result 6: The aggregation process is driven by the team members with median preferences, as the most and the least inequality averse subjects neutralize each other. More inequality averse individuals make larger concessions than the others.

\subsection{Predictive power of the inequality aversion parameters in the Production Games}

In the last section, we examine the predictive power of our inequality aversion measures $\alpha$ and $\beta$ in the Production Games. Yang et al. (2012) predict that because worker or team A always earns more than worker or team B in the PG, effort should depend exclusively and positively on the degree of guilt (with $e_{A}=200 \beta_{A}$ ). We find that worker A's effort levels (mean=57.71, S.D.=31.09), initial proposals (mean=59.27, S.D.=30.53) and team effort levels (mean=58.95, S.D.=29.75) are all significantly higher than 0 (W tests, $p<0.001$ ), providing evidence of guilt. The model predicts that the effort of worker or team B should depend negatively on the degree of envy (with $e_{B}=100-100 \alpha_{B}$ ). We observe that worker B's effort levels (mean=88.33, S.D.=19.93), initial proposals $($ mean=86.81, S.D.=20.87) and team effort levels $($ mean=93.54, S.D.=12.65) are all significantly lower than 100 (W tests, $p<0.001$ ), showing evidence of envy. In contrast to worker A, worker B agrees on higher effort in the team compared to the initial proposals (W tests, $p<0.001)$.

Table 7 reports various Tobit regressions. The dependent variable is the effort levels of worker A, $e_{A}\left(\right.$ model (1)), and worker $\mathrm{B}, e_{B}($ model $(2))$, in the individual PG. The independent variables include the individual $\alpha$ and $\beta$ parameters. Models (3) and (4) for the team PG include the team $\alpha$ and $\beta$ parameters and dummy variables for each treatment (I-NAT being the reference 
category). Models (5) and (6) augment models (3) and (4), respectively, with interaction terms between $\alpha$ and $\beta$ and each treatment because their impact might differ across treatments.

Table 7. Determinants of effort levels in the individual and team Production Games

\begin{tabular}{|c|c|c|c|c|c|c|}
\hline & \multicolumn{2}{|c|}{ Individual Production Game } & \multicolumn{4}{|c|}{ Team Production Game } \\
\hline & $e_{A}(1)$ & $e_{B}(2)$ & $e_{A}(3)$ & $e_{B}(4)$ & $e_{A}(5)$ & $e_{B}(6)$ \\
\hline Envy parameter $(\alpha)$ & - & $\begin{array}{l}-1.139 \\
(1.852)\end{array}$ & - & $\begin{array}{l}-1.279 \\
(1.031)\end{array}$ & - & $\begin{array}{l}-1.090 \\
(1.733)\end{array}$ \\
\hline Guilt parameter $(\beta)$ & $\begin{array}{c}23.575 \\
(15.305)\end{array}$ & - & $\begin{array}{c}43.308 * * * \\
(12.974)\end{array}$ & - & $\begin{array}{c}18.839 \\
(21.388)\end{array}$ & - \\
\hline I-AT treatment & - & - & $\begin{array}{l}-8.705 \\
(6.876)\end{array}$ & $\begin{array}{c}1.800 \\
(3.193)\end{array}$ & $\begin{array}{c}1.075 \\
(17.217)\end{array}$ & $\begin{array}{c}2.306 \\
(4.809)\end{array}$ \\
\hline NAT-I treatment & - & - & $\begin{array}{l}-7.923 \\
(7.194)\end{array}$ & $\begin{array}{c}1.229 \\
(3.101)\end{array}$ & $\begin{array}{c}-39.215 * * * \\
(13.973)\end{array}$ & $\begin{array}{c}1.536 \\
(4.547)\end{array}$ \\
\hline$\alpha *$ I-AT treatment & - & - & - & - & - & $\begin{array}{l}-0.346 \\
(2.436)\end{array}$ \\
\hline$\alpha *$ NAT-I treatment & - & - & - & - & - & $\begin{array}{l}-0.223 \\
(2.511)\end{array}$ \\
\hline$\beta^{*} \mathrm{I}$-AT treatment & - & - & - & - & $\begin{array}{l}-18.466 \\
(31.870)\end{array}$ & - \\
\hline$\beta^{*}$ NAT-I treatment & - & - & - & - & $\begin{array}{c}81.006 * * * \\
(29.438)\end{array}$ & - \\
\hline Observations & 48 & 48 & 94 & 90 & 94 & 90 \\
\hline Right-censored obs. & 9 & 28 & 18 & 64 & 18 & 26 \\
\hline Pseudo $\mathrm{R}^{2}$ & 0.006 & 0.002 & 0.017 & 0.006 & 0.031 & 0.006 \\
\hline Log-likelihood & -201.773 & -118.300 & -392.174 & -158.208 & -386.707 & -158.197 \\
\hline Chi-squared test & 0.137 & 0.540 & 0.003 & 0.593 & 0.000 & 0.860 \\
\hline
\end{tabular}

Note: These regressions are Tobit models. Marginal effects are reported and standard errors are in parentheses. *** indicates significance at the 0.01 level, $* *$ at the 0.05 level, $*$ at the 0.10 level. Teams that did not reach unanimity are excluded.

Table 7 reveals that $\alpha$ and $\beta$ fail to predict behavior in the individual PG. Team B's effort is also not affected by $\alpha$ (see models (4) and (6)). In contrast, model (3) shows that the guilt parameter $\beta$ has significant explanatory power for team A's effort provision, although its magnitude is merely close to half of the theoretical prediction. Model (5) reveals that this effect is driven by the NAT-I treatment. Team effort in this treatment is significantly lower than in INAT, but the dominant effect of $\beta$ in NAT-I makes effort in the two treatments comparable, which supports our last result.

Result 7: The guilt parameter $\beta$ predicts the advantaged teams' behavior in the Production Game, but only when choices are not anonymous. The envy parameter $\alpha$ fails to predict behavior in any configuration of the Production Game. 


\section{DISCUSSION AND CONCLUSION}

Charness and Sutter (2012) write that teams are "less behavioral than individuals" because they are more likely than individuals to make decisions following standard game-theoretic predictions. This claim does not reflect our findings here. Comparing behavior in an Ultimatum Game and in a Modified Dictator Game when people make individual decisions and when they are part of a team does not reveal significant within- or between-subject differences in the degree of envy or guilt between individuals acting in isolation and acting in teams. If teams express less inequality aversion than their members' initial proposals, it is not because bargaining makes people more self-oriented; it is because socially oriented people inflate the degree of guilt and envy in their initial proposals compared to their choices made in isolation in anticipation of the influence of more selfish teammates. The team members who are more inequality averse make more concessions than the others in the aggregation process. This finding suggests a possible bias in the studies comparing individual and team decisions that assume that initial proposals reveal individuals' inner preferences. Initial proposals higher than decisions made in isolation are motivated by strategic reasoning in the absence of information about the others' preferences rather than by social image. During the aggregation process, the individuals with median inequality aversion preferences impose the team decision.

We acknowledge that the absence of major differences in the degree of inequality aversion between teams and individuals may be driven by a number of features in our design. First, individuals bargain in teams without being able to communicate freely with their teammates. Therefore, the pressure of the group and group thinking are probably less intense than when verbal deliberations are possible. The lack of verbal deliberation may explain the difference between our results and those of Balafoutas et al. (2014), who give their subjects the opportunity to chat. An extension of our experiment could explore various modes of communication within teams. Second, another extension could explore other modes of aggregation for individual 
proposals, notably the majority rule. Third, we find that individuals strategically increase their degree of envy or guilt at the onset of the aggregation process to compensate for the expected influence of more selfish teammates. This result may be driven by uncertainty about others' social preferences. A natural extension would consist of informing team members about the individual preferences of each teammate before making any proposal to reduce uncertainty.

We have conducted our experiment in China. Interestingly, our participants express levels of inequality aversion similar to those seen in participants in experiments conducted in Europe, despite their exposure to different political and economic institutions. It would be interesting to explore whether individual and group thinking are more similar in collectivist societies than in more individualized societies. Addressing this question suggests replicating this experiment in other countries.

Finally, we found that the envy parameter predicts neither individual nor team behavior. Blanco et al. (2011) also found no correlation between the inequality aversion parameters at the individual level and behavior in a public goods game and a sequential prisoners' dilemma game. This finding suggests that these parameters also capture other social preferences (like negative reciprocity) that do not play the same role in the Production game. Alternatively, this lack of correlation could result from the fact that preferences are not stable across games and over time. Further investigations are needed to explore this issue. 


\section{REFERENCES}

Ambrus, A. Greiner, B., Pathak, P. (2013). How individual preferences get aggregated in groups - An experimental study. University of New South Wales Discussion Paper, 2013-24.

Baker, R.J., Laury, S. K., Williams, A. W. (2008). Comparing group and individual behavior in lottery-choice experiments. Southern Economic Journal 75, 367-382.

Balafoutas, L., Kerschbamer, R., Kocher, M., Sutter M. (2014). Revealed distributional preferences: Individuals vs. teams. Forthcoming in Journal of Economic Behavior \& Organization.

Bartling, B., Fehr, E., Maréchal, M. A., Schunk, D. (2009). Egalitarianism and Competitiveness. American Economic Review 99(2), 93-98.

Bartling, B., von Siemens, F. (2010). Equal Sharing Rules in Partnerships. Journal of Institutional and Theoretical Economics 166(2), 299-320.

Bénabou, R., Tirole, J. (2006). Incentives and Prosocial Behavior. American Economic Review 96(5), 1652-1678.

Bischoff, I., Krauskopf, T. (2013). Motives of pro-social behavior in individual versus collective decisions - a comparative experimental study. Discussion Paper 19-2013, University of Kassel.

Blanco, M., Engelmann, D., Normann, H. (2011). A Within-Subject Analysis of OtherRegarding Preferences. Games and Economic Behavior 72 (2), 321-338.

Bolton, G.E. (1991). A Comparative Model of Bargaining: Theory and Evidence. American Economic Review 81, 1096-1136.

Bolton, G.E., Ockenfels, A. (2000). ERC: A Theory of Equity, Reciprocity and Competition. American Economic Review 90(1), 166-193.

Bolton, G.E., Ockenfels, A. (2006). Inequality Aversion, Efficiency, and Maximin Preferences in Simple Distribution Experiments: Comment. American Economic Review 96(5), 1906-1911.

Bornstein G., Yaniv I. (1998). Individual and group behavior in the ultimatum game: Are groups more "rational" players? Experimental Economics 1(1), 101-108.

Bornstein, G., Kugler, T., Ziegelmeyer, A. (2004). Individual and group decisions in the centipede game: Are groups more "rational" players? Journal of Experimental Social Psychology 40(5), 599-605.

Bosman, R., Hennig-Schmidt, H., van Winden, F. (2006). Exploring Group Decision Making in a Power-to-Take Experiment. Experimental Economics 9, 35-51.

Brandts, J., Charness, G. (2011). The strategy versus the direct-response method: a first survey of experimental comparisons. Experimental Economics 14, 375-398.

Casari, M., Zhang, J., Jackson, C. (2011). When Do Groups Perform Better than Individuals? A Company Takeover Experiment. Working Paper, University of Bologna.

Cason, T.N, Mui, V.L. (1997). A Laboratory Study in Group Polarisation in the Team Dictator Game. Economic Journal 107(444), 1465-1483.

Charness, G., Sutter, M. (2012). Groups Make Better Self-Interested Decisions. Journal of Economic Perspectives 26(3), 157-176.

Cheung, S.L., Palan, S. (2011). Two heads are less bubbly than one: team decision-making in an experimental asset market. Experimental Economics 15 (3), 373-397. 
Cox, J.C. (2002). Trust, reciprocity, and other-regarding preferences: Groups vs. individuals and males vs. females. In Zwick R., Rapoport, A. (Eds.). Advances in Experimental Business Research. Kluwer Academic Publishers.

Cox, J.C., Hayne, S.C. (2006). Barking up the right tree: Are small groups rational agents? Experimental Economics 9(3), 209-222.

Dannenberg, A., Riechmann, T., Sturm, B., Vogt, C. (2007). Inequality Aversion and Individual Behavior in Public Good Games: An Experimental Investigation. ZEW Discussion Paper 07034, Mannheim.

Engelmann, D., Strobel, M. (2004). Inequality Aversion, Efficiency, and Maximin Preferences in Simple Distribution Experiments. American Economic Review 94(4), 857-869.

Fahr, R., Irlenbusch, B. (2011). Who follows the crowd-Groups or individuals? Journal of Economic Behavior \& Organization 80 (1), 200-209.

Fehr, E., Schmidt, K. (1999). A Theory of Faimess, Competition, and Cooperation. The Quarterly Joumal of Economics 114, 817-868.

Festinger, L., Pepitone, A., Newcomb, T. (1952). Some consequences of deindividuation in a group. Journal of Social Psychology 47, 382-389.

Fischbacher, U. (2007). z-Tree: Zurich Toolbox for Ready-made Economic Experiments. Experimental Economics 10(2), 171-178.

Franzen, A., Pointner, S. (2013). Giving according to preferences: Decision-making in the group dictator game reconsidered. University of Bern Social Sciences Working Paper 2. http://ideas.repec.org/p/bss/wpaper/2.html.

Gill, D., Stone, R. (2012). Desert and inequity aversion in teams. MPRA Paper 36864, University Library of Munich.

Güth, W., Levati, M. V., Ploner, M. (2009). Making the World A Better Place: Experimental Evidence from the Generosity Game. Jena Economic Research Papers 2009-071.

Harrison, G.W., Lau, M.I., Rutström, E.E., Tarazona-Gomez, M. (2012). Preferences over social risk. Oxford Economic Papers 65(1), 25-46.

He, H., Martinsson, P., Sutter, M. (2012). Group decision making under risk: An experiment with student couples. Economics Letters 117, 691-693.

Kocher, M., Sutter, M. (2005). The Decision Maker Matters: Individual versus Group Behaviour in Experimental Beauty-Contest Games. Economic Journal 115(500), 200-223.

Kocher, M., Strauß, S., Sutter, M. (2006). Individual or Team Decision-Making - Causes and Consequences of Self-Selection. Games and Economic Behavior 56(2), 259-270.

Kocher, M. Sutter, M. (2007). Individual versus Group Behavior and the Role of the Decision Making Procedure in Gift-Exchange Experiments. Empirica 34(1), 63-88.

Kölle, F., Sliwka, D., Zhou, N. (2011). Inequality, Inequity Aversion, and the Provision of Public Goods. IZA Discussion Paper 5514, Bonn.

Kugler, T., Bornstein, G., Kocher, M., Sutter, M. (2007). Trust Between Individuals and Groups: Groups Are Less Trusting Than Individuals But Just as Trustworthy. Journal of Economic Psychology 28(6), 646-657.

Kugler, T., Kausel, E.E., Kocher, M.G. (2012). Are groups more rational than individuals? A review of interactive decision making in groups. Cognitive Science 3(4), 471-482.

Luhan, W., Kocher, M., Sutter, M. (2009). Group Polarization in the Team Dictator Game Reconsidered. Experimental Economics 12(1), 26-41. 
Masclet, D., Villeval, M.C. (2008). Punishment, Inequality and Welfare: A Public Good Experiment. Social Choice and Welfare, 31(3), 475-502.

Mohnen, A., Pokorny, K., Sliwka, D. (2008). Transparency, Inequity Aversion, and the Dynamics of Peer Pressure in Teams: Theory and Evidence. Journal of Labor Economics 26(4), 693-720.

Müller, W., Tan, F. (2013). Who acts more like a game theorist? Group and individual play in a sequential market game and the effect of the time horizon. Games and Economic Behavior 82, 658-674.

Reicher, S. D., Spears, R., Postmes, T. (1995). A social identity model of deindividuation phenomena. European Review of Social Psychology 6, 161-198.

Rey-Biel, P. (2008). Inequity aversion and team incentives. Scandinavian Journal of Economics 110(2), 297-320.

Robert C., Carnevale P.J. (1997). Group Choice in Ultimatum Bargaining. Organizational Behavior and Human Decision Processes 72(2), 256-279.

Rockenbach, B., Sadrieh, A., Mathauschek, B. (2007). Teams Take the Better Risks. Journal of Economic Behavior \& Organization 63(3), 412-422.

Sheremeta, R.M., Zhang, J. (2010). Can groups solve the problem of over-bidding in contests? Social Choice and Welfare 35(2), 175-197.

Shupp, R.S., Williams, A.W. (2008). Risk preference differentials of small groups and individuals. Economic Journal 118(525), 258-283.

Sniezek, J.A. (1992). Groups under uncertainty: An examination of confidence and decision making by groups. Organizational Behavior and Human Decision Processes 52, 124-155.

Stahlberg, D., Eller, F., Maass, A., Frey, D. (1995). We knew it all along: Hindsight bias in groups. Organizational Behavior and Human Decision Processes 63(1), 46-58.

Sutter, M. (2005). Are four heads better than two? An experimental beauty-contest game with teams of different size. Economics Letters 88(1), 41-46.

Sutter, M. (2007). Are Teams Prone to Myopic Loss Aversion? An Experimental Study on Individual versus Team Investment Behavior. Economics Letters 97(2), 128-132.

Sutter, M., Kocher, M., Strauß, S. (2009). Individuals and Teams in Auctions. Oxford Economics Paper 61(2), 380-394.

Song, F. (2009). Intergroup trust and reciprocity in strategic interactions: Effects of group decision-making mechanisms. Organizational Behavior and Human Decision Processes 108(1), 164-173.

Tanaka, T., Camerer, C.F., Nguyen, Q. (2010). Risk and Time Preferences: Linking Experimental and Household Survey Data from Vietnam. American Economic Review 100(1), 557-571.

Van Vugt, M., De Cremer, D., Janssen, D.P. (2007). Gender differences in cooperation and competition: The male-warrior hypothesis. Psychological Science 18(1), 19-23.

Yang, Y., Onderstal, S., Schram, A. (2012). Inequity Aversion Revisited. Discussion Paper, University of Amsterdam.

Zhang, J., Casari, M. (2012). How groups reach agreements in risky choices: An experiment. Economic Inquiry 50(2), 502-515. 


\section{Appendix 1. Instructions for the I-NAT treatment (translated from Chinese: instructions for the other treatments available upon request)}

Welcome to this experiment. You have already earned 10 Yuan for showing up on time. During today's experiment, you and the other participants will be asked to make decisions. If you read the following instructions carefully, you can earn a considerable amount of money depending on the decisions you and other participants make. It is therefore important that you take your time to understand the instructions. Please do not communicate with the other participants during the experiment. Should you have any questions, please raise your hand. The experimenters will come to you and answer your question in private.

The experiment consists of several parts. In each part you will be asked to make one or more decisions. You will receive specific instructions before each part begins. The instructions for different parts are different; please read them carefully. Your decisions and answers will remain anonymous unless explicitly specified.

Note that your final earnings from the experiment will be the sum of payoffs from all parts. All payments in the experiment are denoted in points. At the end of the experiment, points will be exchanged to Yuan at a rate of 1 points $=0.03$ Yuan .

Your experimental payoff plus the show-up fee will be paid to you in cash in private in another room at the end of the experiment, by an assistant who is not aware of the content of this experiment.

Please do not touch the computer before you are told so, and please do not fold the screen during the entire experiment.

If you have finished reading these instructions and do not have any question, please wait quietly. Otherwise, please raise your hand and the experimenters will come to you and answer your questions in private.

\section{Part 1}

In this part, there are two roles: Player A and Player B.

Player A is asked to choose between two possible distributions of money between himself/herself and Player B in each of the 21 different decision problems.

Player B knows that A has been asked to make those decisions, and there is nothing s/he can do but accept them.

The role of each participant will be randomly determined as Player A or Player B by the program at the end of the experiment. Which role a participant plays will remain anonymous.

\section{Decisions}

The 21 decision problems will be presented in a chart. Each decision problem will look similar to the following example:

\begin{tabular}{|c|c|c|c|c|}
\hline \multicolumn{2}{|c|}{ Option X } & \multicolumn{2}{|c|}{ Option Y } & \multirow{2}{*}{$\begin{array}{l}\text { Player A's decision } \\
\text { (Choose X or Y) }\end{array}$} \\
\hline Player A's Payoff & Player B's Payoff & Player A's Payoff & Player B's Payoff & \\
\hline 400 & 0 & 100 & 100 & $\mathrm{X}$ \\
\hline
\end{tabular}

\section{You will have to make a decision in the role of Player A.}

Hence, if in this particular decision problem you choose Option X, you decide to keep the 400 points for you, so your paired Player B's payoff will be 0 points. Similarly, if you choose Option Y, you and your paired Player B will receive 100 points each.

The 21 rows will be displayed on the computer screens as illustrated in the below chart. The payoffs in Option X are always 400 points for Player A and 0 point for Player B in all decision problems, while the payoffs in Option Y are the same for both Player A and Player B and the payoffs vary from 0 to 400 points in increments of 20 points, in decision problems \#1 to \#21. 
The 21 decision problems for Player A (Payoffs in point)

\begin{tabular}{|c|c|c|c|c|c|c|}
\hline \multirow{2}{*}{$\begin{array}{l}\text { Decision } \\
\text { problem \# }\end{array}$} & \multicolumn{2}{|c|}{ Option X } & \multicolumn{2}{|c|}{ Option Y } & \multirow{2}{*}{\multicolumn{2}{|c|}{$\begin{array}{l}\text { Player A's decision } \\
\text { (Choose A or B) }\end{array}$}} \\
\hline & $\begin{array}{c}\text { Player A's } \\
\text { Payoff }\end{array}$ & $\begin{array}{c}\text { Player B's } \\
\text { Payoff }\end{array}$ & $\begin{array}{c}\text { Player A's } \\
\text { Payoff }\end{array}$ & $\begin{array}{c}\text { Player B's } \\
\text { Payoff }\end{array}$ & & \\
\hline 1 & 400 & 0 & 0 & 0 & $X$ & $\mathrm{Y}$ \\
\hline 2 & 400 & 0 & 20 & 20 & $X$ & $\mathrm{Y}$ \\
\hline 3 & 400 & 0 & 40 & 40 & $X$ & $\mathrm{Y}$ \\
\hline 4 & 400 & 0 & 60 & 60 & $X$ & $\mathrm{Y}$ \\
\hline 5 & 400 & 0 & 80 & 80 & $X$ & $\mathrm{Y}$ \\
\hline 6 & 400 & 0 & 100 & 100 & $X$ & $\mathrm{Y}$ \\
\hline 7 & 400 & 0 & 120 & 120 & $X$ & $\mathrm{Y}$ \\
\hline 8 & 400 & 0 & 140 & 140 & $X$ & $\mathrm{Y}$ \\
\hline 9 & 400 & 0 & 160 & 160 & $X$ & $\mathrm{Y}$ \\
\hline 10 & 400 & 0 & 180 & 180 & $X$ & $\mathrm{Y}$ \\
\hline 11 & 400 & 0 & 200 & 200 & $X$ & $\mathrm{Y}$ \\
\hline 12 & 400 & 0 & 220 & 220 & $X$ & $\mathrm{Y}$ \\
\hline 13 & 400 & 0 & 240 & 240 & $X$ & $\mathrm{Y}$ \\
\hline 14 & 400 & 0 & 260 & 260 & $X$ & $\mathrm{Y}$ \\
\hline 15 & 400 & 0 & 280 & 280 & $X$ & $\mathrm{Y}$ \\
\hline 16 & 400 & 0 & 300 & 300 & $X$ & $\mathrm{Y}$ \\
\hline 17 & 400 & 0 & 320 & 320 & $X$ & $\mathrm{Y}$ \\
\hline 18 & 400 & 0 & 340 & 340 & $X$ & $\mathrm{Y}$ \\
\hline 19 & 400 & 0 & 360 & 360 & $X$ & $\mathrm{Y}$ \\
\hline 20 & 400 & 0 & 380 & 380 & $X$ & $\mathrm{Y}$ \\
\hline 21 & 400 & 0 & 400 & 400 & $X$ & $\mathrm{Y}$ \\
\hline
\end{tabular}

At the end of the experiment, the computer program will randomly assign you as the role of Player A or Player B. If you are assigned the role of Player A, your payoff will be determined as the amount you have chosen for Player A. If you are assigned the role of Player B, your payoff will be determined as the amount your paired participant has chosen for Player B.

You will have to decide the number of the decision problem until which you choose Option $\mathrm{X}$ and after which you choose Option Y. You will have to enter an integer between 1 and 21 into one of the two boxes on your computer screen as indicated below, to specify your decision.

\section{I choose Option X from decision problem \# 1 to decision problem \# $\square$. \\ I choose Option Y from decision problem \# $\square$ to decision problem \# 21 .}

Once you enter a number in the range 1-20 in the box in the first line, you must fill in the box in the second line with the number equals to one plus the number in the box in the first line. This means that once you start to choose Option $\mathrm{Y}$ in a decision problem, you are not allowed to switch to choose Option $\mathrm{X}$ again in any decision problems occurring after this one.

You are also allowed to make the same choice for all 21 decision problems.

If you always choose Option X, you enter the number 21 in the box in the first line. You must keep the box in the second line blank.

If you always choose Option Y, you enter the number 1 in the box in the second line. You must keep the box in the first line blank.

\section{Examples}

If you enter 21 in the box in the first line, it indicates that you decide to choose Option $\mathrm{X}$ in all 21 decision problems.

If you enter 9 in the box in the first line and 10 in the box in the second line, it indicates that you decide to choose Option X from decision problem \#1 to decision problem \#9 and Option Y from decision problem \#10 to decision problem \#21.

If you enter 1 in the box in the second line, it indicates that you decide to choose Option $\mathrm{Y}$ in all 21 decision problems.

After you have made your choices, please validate your decision by clicking the "Validate" button on your screen.

\section{Payoff determination}


At the end of the experiment, the computer program will randomly pair you with another participant in the room and will randomly assign the two roles. The computer program will randomly choose one of the 21 decision problems, and the decision outcome in the chosen decision problem will then determine your earnings. The matching and role assignment will remain anonymous. You will make the decision as Player A, but the computer program might assign you the role of Player B when determining payoffs. The assignment of roles is random and does not depend on your decisions as Player A.

If you are assigned the role of Player A, you will receive the amount that you have chosen for Player A in the randomly selected decision problem, and the person paired with you will receive the amount that you have chosen for Player B.

If you are assigned the role of Player B, you will receive the amount that the Player A whom you are paired has chosen for Player B in the randomly selected decision problem.

Before this part begins, a few control questions will be asked to make sure that you have fully understood these instructions. If you have finished reading these instructions and do not have any questions, please wait quietly. The control questions will be displayed on your screen soon. Otherwise, please raise your hand and the experimenters will come to you and answer your questions in private.

\section{Part 2}

In this part, there are two roles: Player A and Player B.

Player A is asked to choose one of 21 possible distributions of 400 points between her and Player B.

Player B knows that A has been asked to make those decisions, and may either accept the distribution chosen by A or reject it.

If Player B accepts A's proposed distribution, this distribution will be implemented. If B rejects the offer, both receive nothing.

The role of each participant will be randomly determined as Player A or Player B by the program at the end of the experiment. Which role a participant plays will remain anonymous.

\section{Decisions}

The 21 decision problems for Player A and Player B will be presented in a chart. Each decision problem will look similar to the following example:

\begin{tabular}{|c|c|c|c|c|}
\hline \multicolumn{2}{|c|}{ Distribution chosen by Player A } & \multirow{2}{*}{ Option X } & \multirow{2}{*}{ Option Y } & \multirow{2}{*}{$\begin{array}{l}\text { Player B's decision } \\
\text { (Choose X or Y) }\end{array}$} \\
\hline Player A's Payoff & Player B's Payoff & & & \\
\hline 300 & 100 & Reject & Accept & $\mathrm{X}$ \\
\hline
\end{tabular}

\section{You will have to make decisions in the roles of both Player A and Player B.}

In the latter case, you will have to decide whether you reject or accept each of A's possible 21 proposed distributions. In this example, if you choose Option X, it rejects your paired Player A's proposed distribution and both of your payoffs will be 0 points. If you choose Option Y, A's proposed distribution is accepted; you will receive 100 points and your paired Player A will receive 300 points.

The following chart showing the 21 decision problems will be displayed on your computer screen. The 21 decision problems illustrate the 21 possible distributions of 400 points proposed by Player A, respectively. For decision problems \#1 to \#21, the payoff distributed to Player A reduces from 400 to 0 in increments of 20 points, while the payoff distributed to Player B increases from 0 to 400 in the same increments of 20 points. 
The 21 decision problems for Player B (Payoffs in point)

\begin{tabular}{ccccccc}
\hline \multirow{2}{*}{$\begin{array}{c}\text { Decision } \\
\text { problem }\end{array}$} & $\begin{array}{c}\text { Distribution proposed by } \\
\text { Player A }\end{array}$ & $\begin{array}{c}\text { Player A's } \\
\text { Payoff }\end{array}$ & $\begin{array}{c}\text { Player B's } \\
\text { Payoff }\end{array}$ & Option X & Option Y & $\begin{array}{c}\text { Player B's decision } \\
\text { (Choose X or Y) }\end{array}$ \\
\cline { 2 - 3 } 1 & 400 & 0 & Reject & Accept & X & Y \\
2 & 380 & 20 & Reject & Accept & X & Y \\
3 & 360 & 40 & Reject & Accept & X & Y \\
4 & 340 & 60 & Reject & Accept & X & Y \\
5 & 320 & 80 & Reject & Accept & X & Y \\
6 & 300 & 100 & Reject & Accept & X & Y \\
7 & 280 & 120 & Reject & Accept & X & Y \\
8 & 260 & 140 & Reject & Accept & X & Y \\
9 & 240 & 160 & Reject & Accept & X & Y \\
10 & 220 & 180 & Reject & Accept & X & Y \\
11 & 200 & 200 & Reject & Accept & X & Y \\
12 & 180 & 220 & Reject & Accept & X & Y \\
13 & 160 & 240 & Reject & Accept & X & Y \\
14 & 140 & 260 & Reject & Accept & X & Y \\
15 & 120 & 280 & Reject & Accept & X & Y \\
16 & 100 & 300 & Reject & Accept & X & Y \\
17 & 80 & 320 & Reject & Accept & X & Y \\
18 & 60 & 340 & Reject & Accept & X & Y \\
19 & 40 & 360 & Reject & Accept & X & Y \\
20 & 20 & 380 & Reject & Accept & X & Y \\
21 & 0 & 400 & Reject & Accept & X & Y \\
\hline \hline
\end{tabular}

In the role of Player A, you will have to decide how to distribute 400 points payoff between Player A and Player B as stated in one of the 21 decision problems. You will have to enter an integer between 1 and 21 in the box on your computer screen as indicated below, to specify your decision.

I decide to distribute the 400 points payoff between me and my paired Player $B$ as the way stated in decision problem \#

In the role of Player B, you will have to decide whether you reject or accept each of A's possible 21 proposed distributions. You will have to decide the number of the Player A's proposal until which you reject Player A's proposals (i.e., choose Option X) and after which you accept Player A's proposals (choose Option Y). You will have to enter an integer between 1 and 21 into one of the two boxes on your computer screen as indicated below, to specify your decision.

I reject the distribution (choose Option $\mathrm{X}$ ) as shown from decision problem \# 1 to decision problem \#

\section{I accept the distribution (choose Option Y) as shown from decision problem \# $\square$ to decision problem \# 21.}

Once you enter a number in the range 1-20 in the box in the first line, you must fill in the box in the second line with the number equals to one plus the number in the box in the first line. This means that once you start to accept Player A's proposal in a decision problem, you are not allowed to switch to rejecting the proposals again in any decision problems occurring after this one.

You are also allowed to make the same choice for all 21 decision problems.

If you always reject the proposals of Player A, you enter the number 21 in the box in the first line. You must keep the box in the second line blank.

If you always accept the proposals of Player A, you enter the number 1 in the box in the second line. You must keep the box in the first line blank.

\section{Examples}


If you enter 21 in the box in the first line, it indicates that you decide to reject Player A's proposals (choose Option $\mathrm{X})$ in all 21 decision problems.

If you enter 9 in the box in the first line and 10 in the box in the second line, it indicates that you decide to reject Player A's proposals (choose Option X) from decision problem \#1 to decision problem \#9 and accept the proposals (choose Option Y) from decision problem \#10 to decision problem \#21.

If you enter 1 in the box in the second line, it indicates that you decide to accept Player A's proposals (choose Option Y) in all 21 decision problems.

After you have made your choices, please validate your decisions by clicking the "Validate" button on your screen.

\section{Payoff determination}

At the end of the experiment, the computer program will randomly pair you with another participant in the room and randomly assign the two roles. The assigned roles and decision outcomes of the two matched participants will then determine your earnings. The matching and the role assignment will remain anonymous.

If you are assigned the role of Player A at the end of the experiment, you will receive the payoff you have chosen for yourself only if your paired person B accepts your offer. Otherwise, both will receive nothing.

If you are assigned the role of Player B at the end of the experiment, you will receive the payoff that your paired Player A has chosen for B, only if you accept that particular offer. Otherwise, both will receive nothing.

Before this part begins, a few control questions will be asked to make sure that you have fully understood these instructions. If you have finished reading these instructions and do not have any question, please wait quietly. The control questions will be displayed on your screen soon. Otherwise, please raise your hand and the experimenters will come to you and answer your questions in private.

\section{Part 3}

This part is identical to Part 1, with one exception. The only difference from Part 1 is that you are now a member of a team, and your team must make team decisions jointly as one decision-maker. Your team consists of three participants in this room.

Please note that your team consists of members with the ID numbers I, II, and III. The other two members in your team are seated next to you in the same row. Members I, II and III are seated at the left, middle and right of the row, respectively. For example, if you are seated at the far right of your row, the two persons to your left from left to right are members I and II, respectively. If you are seated in the middle of your row, the persons to your left and right are members I and III, respectively. If you are seated at the far-left of your row, the two persons to your right from left to right are members II and III, respectively. Thus, each member's proposal will be identified by the two other members by his ID number.

In the role of Player A, your team has to make a collective team decision on the number of the decision problem until which you choose Option $\mathrm{X}$ and after which you choose Option Y.

Player B makes no decisions.

At the end of the experiment, the computer program will randomly assign your team the role of Player A or the role of Player B.

The three members of the team must propose individual proposals and to enter them on their computer screens independently. Unanimity is required for the three members to reach a collective team decision. The following procedure determines the team decision:

- The three individual proposals will be simultaneously displayed on all members' screens.

- If the three proposals are not identical, a new proposal round starts. Each member must enter a new proposal. Each member may choose the same proposal as in previous rounds or make a different proposal.

- This team decision-making procedure must be repeated until all team members propose an identical number. This proposal will be automatically converted into the team's decision.

- Members have unlimited number of rounds to enter new proposals in a $\mathbf{1 0}$ minute window. Proposals made by each member during previous rounds can be observed in the proposal history box on the righthand side of the screen.

- If team members have not reached an identical proposal after 10 minutes, the computer program will randomly select one of the possible decisions as the team decision. 
Please note that members are not allowed to communicate orally during the entire experiment.

\section{Payoff determination}

The rules of payoffs determination are identical to that in Part 1.

Please note that each member of the team will receive the determined payoff rather than sharing this amount. That is, for the selected decision, each member in your team will receive this amount.

If you have finished reading these instructions and do not have any questions, please wait quietly. The decisionmaking screen will be displayed soon. Please enter your proposal as if you were Player A for this part. Otherwise, please raise your hand and the experimenters will come to you and answer your questions in private.

\section{Part 4}

This part is identical to Part 2, with one exception. The only difference from Part 2 is that now you will be teamed up with the same two other members with the same ID numbers as in Part 3, and your team must make team decisions jointly as one decision-maker.

In the role of Player A, your team will make a collective team decision for the distribution of 400 points payoff between Player A and Player B as stated in one of the 21 decision problems.

In the role of Player B, your team will make a collective team decision on the number of the Player A's proposal until which you reject Player A's proposals (choose Option X) and after which you accept Player A's proposals (choose Option Y).

At the end of the experiment, the computer program will randomly assign your team the role of Player A or the role of Player B.

The three members of the team must propose individual proposals and to enter them on their computer screens independently. Unanimity is required for the three members to reach a collective team decision.

The procedure to determine team decisions is identical to that in Part 3. In the role of Player A, members have unlimited number of rounds to enter new proposals in a 10 minute window. If team members have not reached an identical proposal after 10 minutes, the computer program will randomly select one of the possible decisions as the team decision.

In the role of Player B, the same procedure applies. Team members have again 10 minutes maximum to reach an identical proposal, otherwise the computer program will randomly select one decision as the team decision.

\section{$\underline{\text { Payoff determination }}$}

The rules of payoffs determination are identical to that in Part 2.

Please note that each member of the team will receive the determined payoff rather than sharing this amount. That is, for the selected decision, each member in your team will receive this amount.

If you have finished reading these instructions and do not have any questions, please wait quietly. The decisionmaking screen will be displayed soon. Please enter your proposals as if your team was Player A and Player B, respectively, for this part. Otherwise, please raise your hand and the experimenters will come to you and answer your questions in private.

\section{Part 5}

You are a member of the same team with the two other members with the same ID numbers as in Parts 3 and 4 . In this part, your team will participate in a production game.

The production game involves two working teams, Team A and Team B, who are in charge of Departments 1 and 2, respectively. Each team chooses an effort level (an integer between 0 and 100 that is a multiple of 10, i.e., 0, 10, $20, \ldots, 100)$, which will determine the production of the department the team is in charge of. A team's total income from this game consists of four parts: (1) Basic salary; (2) A bonus dependent on the production of Department 1; (3) A bonus dependent on the production of Department 2; (4) Effort cost, which is dependent on team's own effort level. We introduce each part in turn.

1. Basic salary. The basic salary is 200 points for Team A and 0 point for Team B.

2. Bonus 1. The production of Department 1 will be equally divided between Team A and Team B as Bonus 1 . Production is wholly determined by Team A's effort level. The higher the effort level Team A chooses, the more Department 1 produces, and, hence, the larger Bonus 1 received by both Team A and Team B . 
3. Bonus 2. The production of Department 2 will be equally divided between Team A and Team B as Bonus 2 . Production is wholly determined by Team B's effort level. The higher the effort level Team B chooses, the more Department 2 produces, and, hence, the larger Bonus 2 received by both Team A and Team B .

4. Effort cost. A team bears the cost of each unit of effort input into the department's production. Each unit of effort in Department 1 costs Team A 2 points. Each unit of effort in Department 2 costs Team B 1 point.

For each team, the total payoff from the production game is represented by the following equation:

Total income $=$ Basic salary + Bonus $1+$ Bonus 2 - Effort cost.

Please note that, because Team A's basic salary is 200 points while Team B's is 0, total income for Team A is always higher than Team B regardless of the effort levels chosen by Team A and Team B. Of course, the difference varies with different effort levels chosen by the two teams.

After you enter an effort level, you can immediately view the corresponding potential amount of bonus and effort costs displayed. You may test different effort levels to observe the corresponding variation in total income for Team A and Team B. When make your final decisions, ensure that the numbers in the boxes are correct, and press "Submit" at the bottom of the page.

In this part, you will be randomly paired and assigned the role of Team A or Team B. The results of the random pairing and role assignment will remain anonymous and will not be revealed until the end of the experiment. For this reason, every participant is asked to make a decision as Team A and Team B. At the end of the experiment, your decision for Team A's effort level will only apply if you are assigned the role of the Team A, otherwise, if you are assigned the role of Team B, your decision for Team B's effort level will adopted.

$\underline{\text { Team decisions }}$

The three members of the team must propose individual proposals and to enter them into their computers independently. Unanimity is required for the three members to reach a collective team decision. Team members must propose individual proposals simultaneously in both the roles of Team A and Team B on the same computer screens. The procedure to determine team decisions is identical to that in Parts 3 and 4.

In the roles of Team A and Team B, members have unlimited number of rounds to enter new decisions in a 20 minute window.

If team members have not reached identical decisions in the roles of the two types of working teams after 20 minutes, the computer program will randomly select one of the possible decisions as the team decisions for Team A and for Team B, respectively.

\section{Payoff determination}

Each of the members will receive the determined payoff for a working team rather than sharing this amount. That is, for the selected decision, each of the members in your team will receive this amount.

If you have finished reading these instructions and do not have any questions, please wait quietly. The decisionmaking screen will be displayed soon. Please enter your proposals as if your team was Team A and Team B, respectively, for this part. Otherwise, please raise your hand and the experimenters will come to you and answer your questions in private. 


\section{Appendix 2. Tables and Figures}

Table A1. Influence of the type of decision and of the treatment on the disadvantageous and advantageous inequality aversion (envy and guilt) parameters

\begin{tabular}{lcccc}
\hline Variables & \multicolumn{2}{c}{ Envy parameter $(\alpha)$} & \multicolumn{2}{c}{ Guilt parameter $(\beta)$} \\
\hline & $(1)$ & $(2)$ & $(3)$ & $(4)$ \\
\hline Ref.: First individual decision in I-I & - & - & - & - \\
Second decision in I-I & -0.036 & -0.033 & 0.008 & 0.007 \\
& $(0.219)$ & $(0.159)$ & $(0.036)$ & $(0.032)$ \\
Individual decision in I-AT & 0.111 & 0.111 & 0.062 & 0.055 \\
& $(0.327)$ & $(0.242)$ & $(0.053)$ & $(0.048)$ \\
Initial proposal in I-AT & $0.622^{*}$ & $0.485^{* *}$ & $0.095^{*}$ & $0.085^{*}$ \\
& $(0.326)$ & $(0.241)$ & $(0.053)$ & $(0.048)$ \\
Team decision in I-AT & 0.583 & $0.487^{*}$ & 0.043 & 0.039 \\
& $(0.380)$ & $(0.279)$ & $(0.061)$ & $(0.055)$ \\
Individual decision in I-NAT & -0.121 & -0.079 & 0.001 & 0.001 \\
& $(0.318)$ & $(0.236)$ & $(0.053)$ & $(0.047)$ \\
Initial proposal in I-NAT & 0.338 & 0.308 & $0.088^{*}$ & $0.079^{*}$ \\
& $(0.318)$ & $(0.236)$ & $(0.053)$ & $(0.047)$ \\
Team decision in I-NAT & 0.281 & 0.285 & 0.087 & 0.078 \\
& $(0.365)$ & $(0.269)$ & $(0.061)$ & $(0.054)$ \\
Individual decision in NAT-I & 0.016 & 0.0305 & $-0.099^{*}$ & $-0.089^{*}$ \\
& $(0.321)$ & $(0.238)$ & $(0.053)$ & $(0.047)$ \\
Initial proposal in NAT-I & 0.379 & 0.301 & -0.071 & -0.063 \\
& $(0.321)$ & $(0.238)$ & $(0.053)$ & $(0.048)$ \\
Team decision in NAT-I & 0.063 & 0.120 & $-0.144 * *$ & $-0.129^{* *}$ \\
& $(0.370)$ & $(0.272)$ & $(0.062)$ & $(0.055)$ \\
Constant & $0.905^{* * *}$ & - & $0.471^{* * *}$ & - \\
& $(0.260)$ & & $(0.043)$ & 754 \\
\hline Observations & 726 & 726 & 754 & 60 \\
Left-censored observations & - & 77 & - & 25 \\
Right-censored observations & - & 83 & - & 330 \\
Number of subjects & 318 & 318 & 330 & -128.100 \\
Chi-squared test & - & $<0.001$ & - & - \\
Log-likelihood & - & 1209.036 & - & \\
\hline
\end{tabular}

Notes: Regressions (1) and (3) are random-effects interval regression models. Regressions (2) and (4) are random-effects tobit models based on point estimates. Reported values are marginal effects. Standard errors are in parentheses. $* * *$ indicate significance at the 0.01 level, ** at the 0.05 level, * at the 0.10 level. 
Table A2. Comparisons among individual and team decisions based on the estimates of Table A1 ( $p$ value from Chi-squared tests)

\begin{tabular}{|c|c|c|c|c|}
\hline & \multicolumn{2}{|c|}{ Envy parameter $(\alpha)$} & \multicolumn{2}{|c|}{ Guilt parameter $(\beta)$} \\
\hline & (1) & (2) & (3) & (4) \\
\hline TD vs. ID in I-AT & $0.067 *$ & $0.043 * *$ & 0.635 & 0.634 \\
\hline TD vs. ID in I-NAT & $0.092 *$ & $0.034 * *$ & $0.028 * *$ & $0.028 * *$ \\
\hline TD $v s$. ID in NAT-I & 0.846 & 0.609 & 0.267 & 0.266 \\
\hline IIP $v s$. ID in I-AT & $0.003 * * *$ & $0.002 * * *$ & 0.207 & 0.206 \\
\hline IIP $v s$. ID in I-NAT & $0.003^{* * *}$ & $0.001 * * *$ & $0.001 * * *$ & $0.001 * * *$ \\
\hline IIP vs. ID in NAT-I & $0.023 * *$ & $0.019 * *$ & 0.283 & 0.282 \\
\hline TD vs. IIP in I-AT & 0.878 & 0.990 & 0.193 & 0.192 \\
\hline TD $v s$. IIP in I-NAT & 0.810 & 0.893 & 0.974 & 0.977 \\
\hline TD $v s$. IIP in NAT-I & 0.196 & 0.306 & $0.071^{*}$ & $0.070 *$ \\
\hline (TD-ID) in I-AT vs. (TD-ID) in I-NAT & 0.841 & 0.962 & $0.060^{*}$ & $0.059 *$ \\
\hline (TD-ID) in I-NAT vs. (TD-ID) in NAT-I & 0.298 & 0.264 & $0.020 * *$ & $0.020 * *$ \\
\hline (IIP-ID) in I-AT $v s$. (IIP-ID) in I-NAT & 0.819 & 0.936 & 0.136 & 0.136 \\
\hline (IIP-ID) in I-NAT $v s$. (IIP-ID) in NAT-I & 0.667 & 0.467 & 0.106 & 0.106 \\
\hline (TD-IIP) in I-AT $v s$. (TD-IIP) in I-NAT & 0.960 & 0.920 & 0.366 & 0.364 \\
\hline (TD-IIP) in I-NAT vs. (TD-IIP) in NAT-I & 0.448 & 0.522 & 0.202 & 0.201 \\
\hline ID first time $v s$. ID second time in I-I & 0.869 & 0.836 & 0.832 & 0.832 \\
\hline ID in I-I $v s$. ID in I-AT & 0.735 & 0.646 & 0.244 & 0.243 \\
\hline ID in I-I $v s$. ID in I-NAT & 0.705 & 0.737 & 0.988 & 0.987 \\
\hline ID in I-I $v s$. ID in NAT-I & 0.960 & 0.898 & $0.063 *$ & $0.062 *$ \\
\hline ID in I-AT $v s$. ID in I-NAT & 0.393 & 0.341 & 0.161 & 0.161 \\
\hline ID in I-AT $v s$. ID in NAT-I & 0.729 & 0.690 & $<0.001 * * *$ & $<0.001 * * *$ \\
\hline ID in I-NAT $v s$. ID in NAT-I & 0.604 & 0.574 & $0.022 * *$ & $0.021 * *$ \\
\hline
\end{tabular}

Notes: Models (1) and (3) are based on the Interval regressions of Table A1 and models (2) and (4) on the tobit models based on point estimates of Table A1. *** indicate significance at the 0.01 level, ** at the 0.05 level, * at the 0.10 level. ID for individual decisions, IIP for individual initial proposals, and TD for team decisions. 
Table A3. Interval regressions of the envy and guilt parameters, by treatment

\begin{tabular}{|c|c|c|c|c|c|c|c|c|}
\hline & \multicolumn{4}{|c|}{ Envy parameter $(\alpha)$} & \multicolumn{4}{|c|}{ Guilt parameter $(\beta)$} \\
\hline & $\begin{array}{l}\text { Indiv. } \\
\text { decision } \\
(1)\end{array}$ & $\begin{array}{l}\text { Ind. initial } \\
\text { proposal } \\
\text { (2) }\end{array}$ & $\begin{array}{c}\text { Team } \\
\text { Decision } \\
(3)\end{array}$ & $\begin{array}{l}\text { Pooled indiv. } \\
\text { decision \& indiv. } \\
\text { initial prop. (4) }\end{array}$ & $\begin{array}{l}\text { Indiv. } \\
\text { Decision } \\
(5)\end{array}$ & $\begin{array}{l}\text { Ind. initial } \\
\text { proposal } \\
(6)\end{array}$ & $\begin{array}{c}\text { Team } \\
\text { decision } \\
(7)\end{array}$ & $\begin{array}{c}\text { Pooled indiv. } \\
\text { decision \& indiv. } \\
\text { initial prop. (8) }\end{array}$ \\
\hline Team decision first & -0.022 & -0.093 & -0.183 & -0.167 & $-0.139 * * *$ & $-0.075 * * *$ & $-0.092 * * *$ & $-0.168 * * *$ \\
\hline (NAT-I treatment) & $(0.214)$ & $(0.238)$ & $(0.271)$ & $(0.257)$ & $(0.040)$ & $(0.029)$ & $(0.024)$ & $(0.037)$ \\
\hline Non-anonymity & - & $\begin{array}{c}0.012 \\
(0.246)\end{array}$ & $\begin{array}{c}0.148 \\
(0.486)\end{array}$ & - & - & $\begin{array}{c}0.004 \\
(0.029)\end{array}$ & $\begin{array}{c}0.062 \\
(0.068)\end{array}$ & - \\
\hline $\begin{array}{l}\text { Individual decision- } \\
\text { making }\end{array}$ & - & - & - & $\begin{array}{l}-0.540^{*} \\
(0.321)\end{array}$ & - & - & - & $\begin{array}{l}-0.089 * \\
(0.047)\end{array}$ \\
\hline $\begin{array}{l}\text { Number of males in the } \\
\text { team }\end{array}$ & - & - & $\begin{array}{c}0.174 \\
(0.274)\end{array}$ & - & - & - & $\begin{array}{l}-0.017 \\
(0.036)\end{array}$ & - \\
\hline $\begin{array}{l}\text { Number of males in the } \\
\text { team } * \text { Non-anonymity }\end{array}$ & - & - & $\begin{array}{l}-0.015 \\
(0.326)\end{array}$ & - & - & - & $\begin{array}{l}-0.024 \\
(0.044)\end{array}$ & - \\
\hline$\alpha$ in individual decision & - & $\begin{array}{c}0.871 * * * \\
(0.072)\end{array}$ & - & - & - & - & - & - \\
\hline$\beta$ in individual decision & - & - & - & - & - & $\begin{array}{c}0.697 * * * \\
(0.042)\end{array}$ & - & - \\
\hline $\begin{array}{l}\text { Team mean } \alpha \text { in } \\
\text { individual decision }\end{array}$ & - & - & $\begin{array}{c}0.913 * * * \\
(0.127)\end{array}$ & - & - & - & - & - \\
\hline $\begin{array}{l}\text { Team mean } \beta \text { in } \\
\text { individual decision }\end{array}$ & - & - & - & - & - & - & $\begin{array}{c}0.862 * * * \\
(0.096)\end{array}$ & - \\
\hline Male & $\begin{array}{c}-0.017 \\
(0.205)\end{array}$ & $\begin{array}{c}0.260 \\
(0.208)\end{array}$ & - & $\begin{array}{c}0.157 \\
(0.237)\end{array}$ & $\begin{array}{l}-0.068^{*} \\
(0.038)\end{array}$ & $\begin{array}{l}-0.035 \\
(0.025)\end{array}$ & - & $\begin{array}{c}-0.069 * * \\
(0.034)\end{array}$ \\
\hline Rural register & $\begin{array}{l}-0.217 \\
(0.216)\end{array}$ & $\begin{array}{c}0.075 \\
(0.222)\end{array}$ & - & $\begin{array}{l}-0.088 \\
(0.249)\end{array}$ & $\begin{array}{l}-0.044 \\
(0.040)\end{array}$ & $\begin{array}{c}0.079 * * * \\
(0.026)\end{array}$ & - & $\begin{array}{c}-0.087 * * \\
(0.035)\end{array}$ \\
\hline $\begin{array}{l}\text { Number of close } \\
\text { friends }\end{array}$ & $\begin{array}{c}0.045 \\
(0.042)\end{array}$ & $\begin{array}{c}0.066 \\
(0.045)\end{array}$ & - & $\begin{array}{l}0.090^{*} \\
(0.049)\end{array}$ & $\begin{array}{c}0.018 * * \\
(0.008)\end{array}$ & $\begin{array}{c}0.008 \\
(0.005)\end{array}$ & - & $\begin{array}{c}0.017 * * \\
(0.007)\end{array}$ \\
\hline $\begin{array}{l}\text { Acquaintances in the } \\
\text { session }\end{array}$ & $\begin{array}{l}-0.105 \\
(0.210)\end{array}$ & $\begin{array}{l}-0.258 \\
(0.215)\end{array}$ & - & $\begin{array}{l}-0.395 \\
(0.243)\end{array}$ & $\begin{array}{l}-0.040 \\
(0.040)\end{array}$ & $\begin{array}{l}0.048 * \\
(0.026)\end{array}$ & & $\begin{array}{c}0.013 \\
(0.035)\end{array}$ \\
\hline Other controls & Yes & Yes & No & Yes & Yes & Yes & No & Yes \\
\hline Constant & $\begin{array}{c}0.438 \\
(1.324)\end{array}$ & $\begin{array}{c}0.024 \\
(1.328) \\
\end{array}$ & $\begin{array}{l}-0.247 \\
(0.408)\end{array}$ & $\begin{array}{c}0.564 \\
(1.550) \\
\end{array}$ & $\begin{array}{c}0.185 \\
(0.238) \\
\end{array}$ & $\begin{array}{c}0.063 \\
(0.154) \\
\end{array}$ & $\begin{array}{l}0.120^{*} \\
(0.071)\end{array}$ & $\begin{array}{c}0.137 \\
(0.215)\end{array}$ \\
\hline Observations & 318 & 270 & 90 & 318 & 330 & 282 & 94 & 330 \\
\hline Chi-squared & 0.975 & 0 & $2.20 \mathrm{e}-08$ & 0.242 & 0.095 & 0 & 0 & $9.83 e-05$ \\
\hline Log-likelihood & -951.452 & -681.244 & -234.027 & -900.767 & -985.559 & -714.195 & -231.250 & -965.465 \\
\hline
\end{tabular}


Notes: Marginal effects are reported and standard errors are in parentheses. *** indicates significance at the 0.01 level, ** at the 0.05 level, $*$ at the 0.10 level. The other control variables include age, Han ethnicity, number of siblings, importance of social image, having already participated in an experiment, occupational activity while studying, being a member of the Communist party, studying economics, years of education, family size, number of siblings, income. 


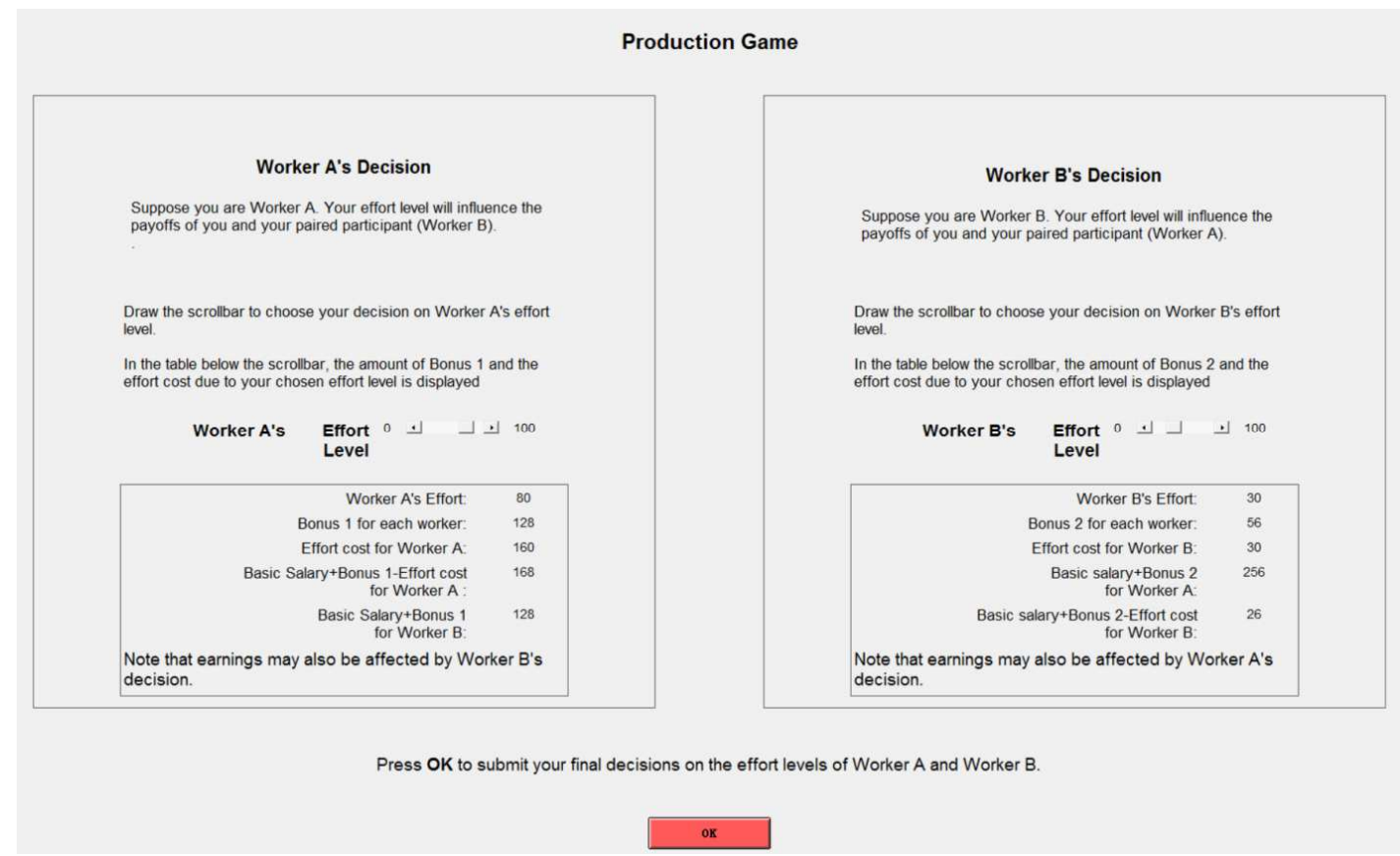

Figure A1. Screenshot of the individual Production Game 


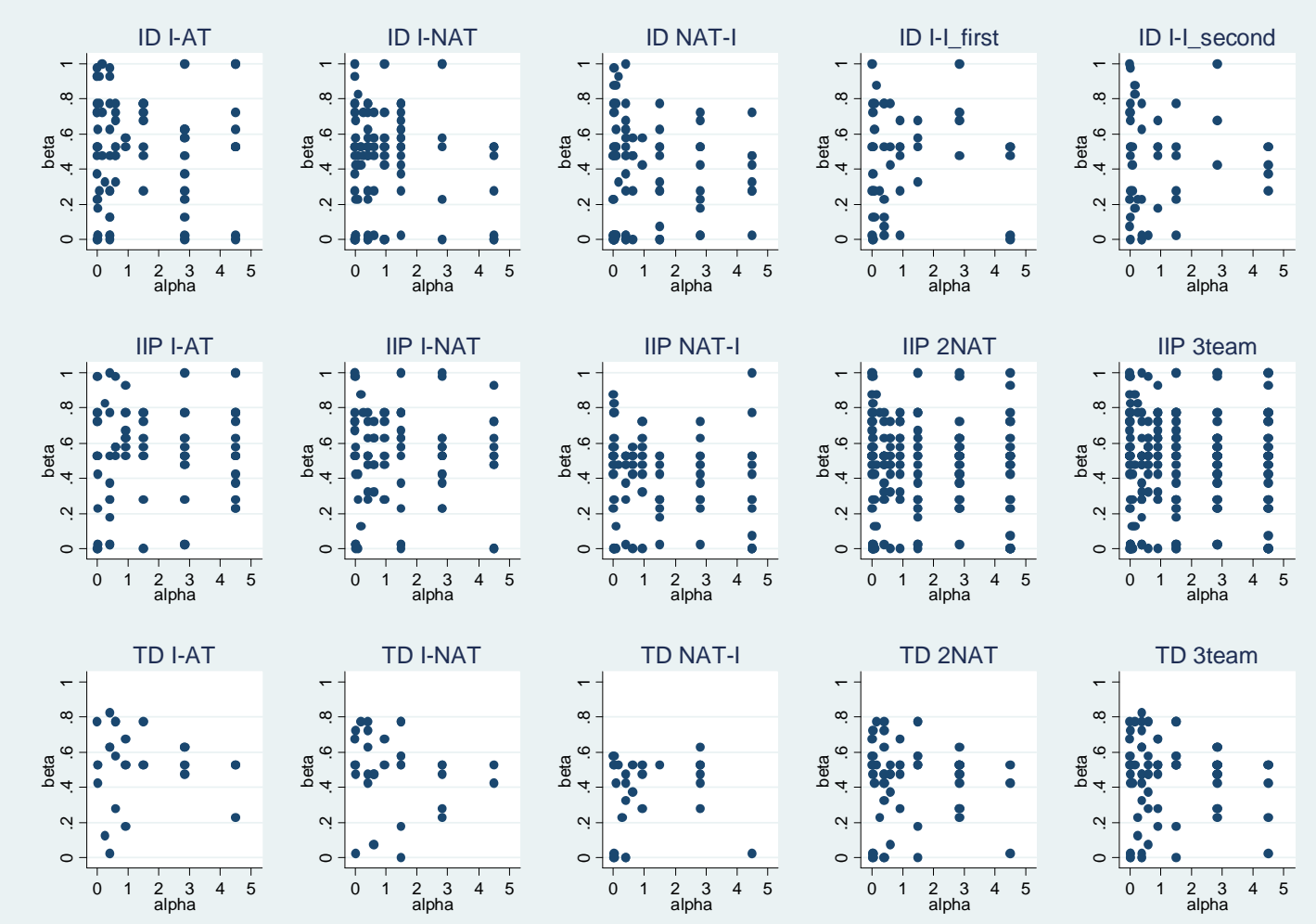

Notes: "2NAT" refers to the two treatments with non-anonymous team decisions; "3team" refers to the three treatments with team decisions

Figure A2. $\alpha-\beta$ joint distribution for individual decisions (ID), individual initial proposals (IIP) and team decisions (TD) 